\title{
Key Characteristics of a Floating Slab Track Based on Longitudinal Interaction Analysis
}

\author{
Goo Sam Jee, ${ }^{1}$ Huan Ha Nguyen, ${ }^{1}$ Seung Yup Jang, \\ Heeyoung Lee $\mathbb{D}^{1,},{ }^{1,3}$ and Wonseok Chung $\mathbb{i D}^{1}$ \\ ${ }^{1}$ Department of Civil Engineering, Kyung Hee University, Yongin, Gyeonggi-do 17104, Republic of Korea \\ ${ }^{2}$ Department of Transportation System Engineering, Graduate School of Transportation, Korea National University of Transportation, \\ Gyeonggi-do 16106, Republic of Korea \\ ${ }^{3}$ Department of Civil Engineering, University of Colorado Denver, 1200 Larimer Street, Denver, CO 80217, USA
}

Correspondence should be addressed to Heeyoung Lee; heeyoung0908@khu.ac.kr and Wonseok Chung; wschung@khu.ac.kr

Received 26 January 2018; Revised 23 April 2018; Accepted 6 May 2018; Published 26 July 2018

Academic Editor: Francesco Pellicano

Copyright (C) 2018 Goo Sam Jee et al. This is an open access article distributed under the Creative Commons Attribution License, which permits unrestricted use, distribution, and reproduction in any medium, provided the original work is properly cited.

\begin{abstract}
The passage of railway vehicles produces mechanical vibrations across an extensive range of frequencies. A floating slab track (FST) has recently been proposed and constructed in Korea to reduce the vibrations and noise that result from typical railway operation. The main objective of this study is to investigate the behavior of an FST by means of an interaction analysis of a trackslab-isolator. Key FST parameters considered in this study are additional rail stress, slab stress and displacement, and stopper displacement. The FST parameters include slab length and thickness, isolator stiffness, and longitudinal stiffness. The sensitivity of the key characteristics of each FST parameter is examined. This study also determines the maximum length of an FST based on the maximum additional rail stress criterion. Finally, a formula to predict maximum additional rail stress is proposed for the design of FST systems.
\end{abstract}

\section{Introduction}

Numerous high-speed railway tracks have recently been developed and constructed in Korea. The passage of railway vehicles produces mechanical vibrations across an extensive range of frequencies. Thus, the placement of structural vibration isolation systems is required to decrease vibrations and noise. Floating slab track (FST) systems are the most effective for prevention of mechanical vibrations and groundborne noise generated by passing trains $[1,2]$. FST systems have been successfully installed in various civil structures such as tunnels, high-speed rail lines, bridges, and viaducts. Various different types of FST systems have been improved and constructed around the world in places such as Japan, Europe, and North America [3, 4]. In Korea, an FST system, such as the one shown in Figure 1, has been successfully developed and tested, and one is currently being constructed in the test-bed of a commercial railway line.
FST systems typically consist of simple masses and springs that can isolate vibrations due to wheel-rail interactions. In an FST system, a continuous welded rail (CWR) is fixed to a massive concrete slab through rail pads with isolators under the concrete track. Although an FST is expensive and requires greater section heights because of the isolator, this relatively high cost is more than compensated for by the reduced noise and vibration.

Grootenhuis studied the effects of an FST on noise and vibrations [6]. Dynamic analysis was used, and the results show that the FST system can not only eliminate noise and vibrations but also avoid resonance. The effects of noise and vibration on railway tracks were later studied by several researchers with various two- and three-dimensional finite element models [7-9]. Again, significant reductions in noise and vibration were found in various conditions. However, the effect of slab length is an important factor in FST development which has not yet been fully researched [10]. Slab length 


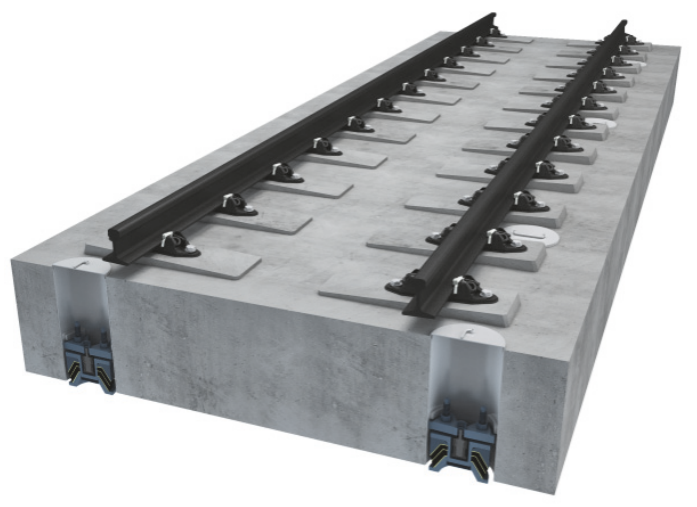

(a) An FST system

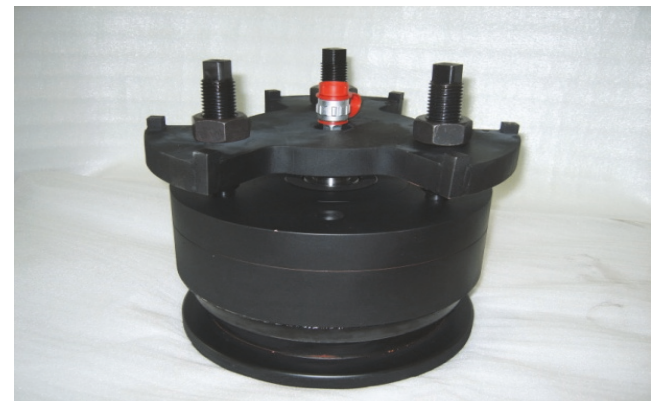

(b) Isolator

FIGURE 1: Typical configuration of an FST system and isolator.

influences many aspects of an FST system, such as additional rail stress, tensile slab stress, and slab displacement. The relationships between additional rail stress and other FST parameters should be considered as particularly significant associations in the design of an FST system [11].

The key purpose of this study is to investigate the behavior of an FST by a track-slab-isolator interaction analysis. The key behaviors of an FST considered in this study are additional rail stress, slab stress and displacement, and stopper displacement. FST parameters include slab length and thickness, isolator stiffness, and longitudinal stiffness. The sensitivity of each parameter to the key response of an FST was examined based on interaction analysis. This study also determines the maximum length of an FST based on the maximum additional rail stress criterion. There are no fully accepted design criteria in FST systems for railway tracks, especially pertaining to recommendations on the length of the slab. In this study, the maximum additional tensile and compressive rail stress limit is $92 \mathrm{MPa}$, as described in the International Union of Railways (UIC) code [11]. Finally, a formula is proposed to predict the maximum additional rail stress for the design of an FST system.

\section{Interaction Analysis Model}

2.1. Research Methodology. The approach adopted in this work includes the development of a reliable track-slabisolator interaction analysis model and the postulation and verification of a formula for additional rail stress. First, the dimensions of a standard FST were chosen based on experimental tests on a currently under-development FST [12]. Additionally, based on previous research [10], the dimensions of a standard FST were chosen, with a length of $34.5 \mathrm{~m}$ and a thickness of $0.54 \mathrm{~m}$. Second, the applicable range for each parameter was selected to fully investigate the behavior of FST systems under various conditions.

In this study, the standard values of an FST system were modeled and fully populated with key variables such as slab length and thickness, vertical isolator stiffness, and Young's modulus. In an FST system, the longitudinal displacements are essential variables because they are generated by additional rail stresses; this necessitates the evaluation of these variables. Three stopper configurations are considered for analysis; these slab track configurations with and without stoppers are illustrated in Figure 2.

At both ends of the concrete slab track, bed blocks were installed, as shown in Figure 3, because the additional rail stresses change rapidly in this region. When the train operates over the transition between the embankment and the FST (at both ends of the concrete slab track), a vehicle-track force is created at the transition due to an abrupt change in track stiffness. As a result, rail stresses of increased magnitude are generated in this area [13].

2.2. Finite Element Model. In this study, numerical simulations were implemented using the ABAQUS package [14]. ABAQUS has an extensive range of abilities for simulation of linear and nonlinear functions, and the elements for the FST system model were carefully selected from the various elements the software is capable of modeling. In this study, an FST system was modeled by the connections between the rail, slab, isolator, bed block, and stopper (if any). All analysis elements were considered in a simplified two-dimensional (2D) finite element model (FEM). Figure 3 illustrates a typical detailed model used in this study for visualization of the FST system. CWRs and concrete slabs were modeled with Timoshenko beam elements that allow for transverse shear deformation. The length of a CWR can be quite long, up to several kilometers, but the floating slab is many times shorter. Therefore, an infinite Timoshenko beam (B21) was selected for the rail and a finite one was selected for the floating slab. The rail and concrete slab were assumed to be linear, elastic, and isotropic.

The upper beam elements (rail) are fixed at both ends and interact with the lower beam element (floating slab) by means of the track stiffness. The connection was modeled as a two-node spring element. The spring exhibits nonlinear behavior in the longitudinal direction and linear behavior in the vertical direction. The longitudinal stiffness of the track is defined in UIC code 774-3R [11] and is a function of the 
L

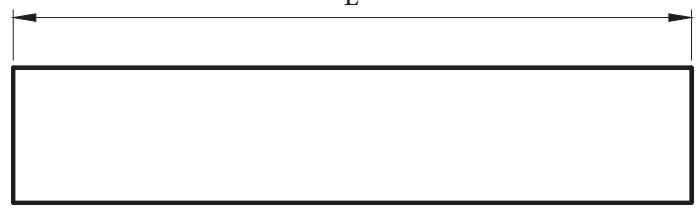

(a) Case A (no stoppers)

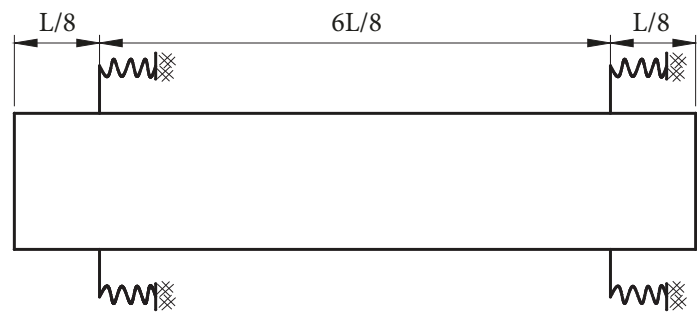

(b) Case B (2 stoppers)

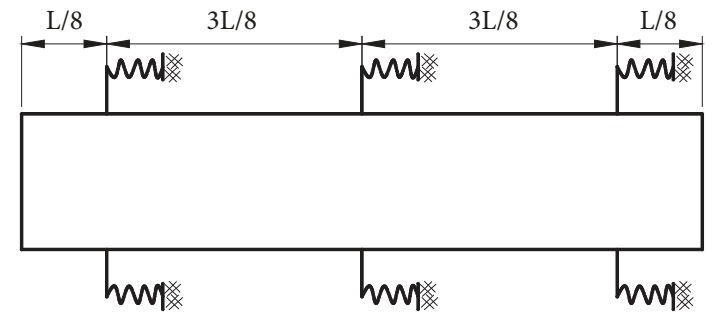

(c) Case C (3 stoppers)

FIGURE 2: Stopper configurations of an FST system (plan view).

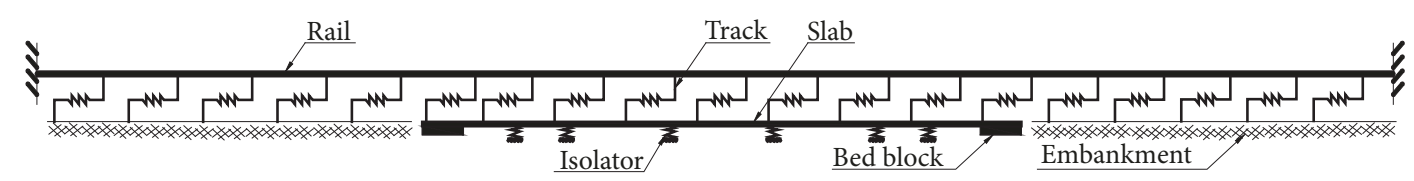

Figure 3: Analysis model of an FST system.

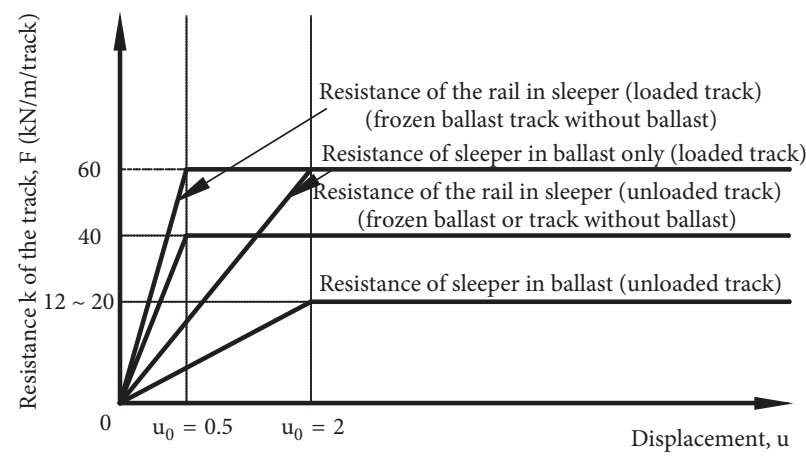

FIGURE 4: Track stiffness.

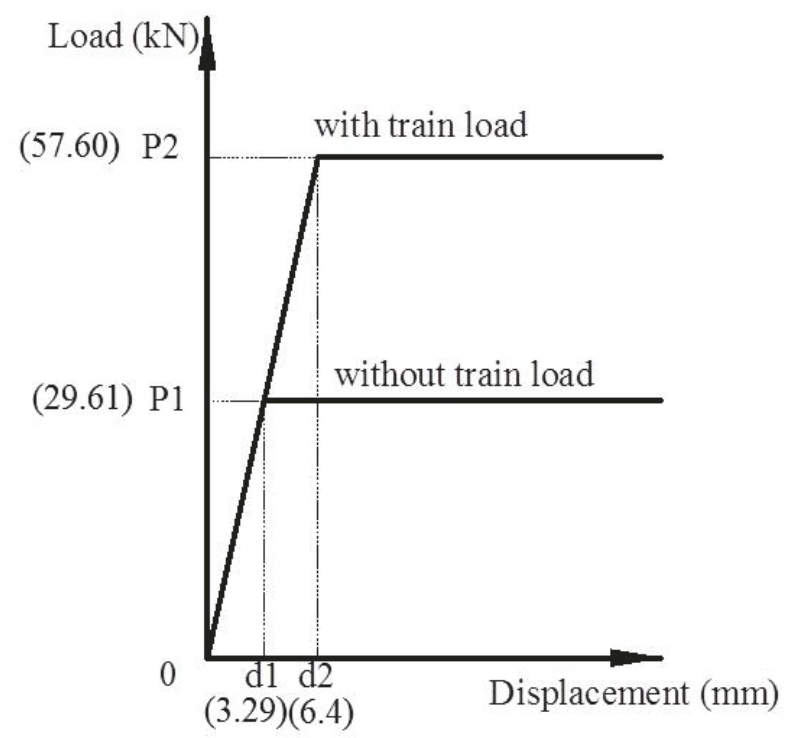

FIGURE 5: Longitudinal isolator stiffness. 


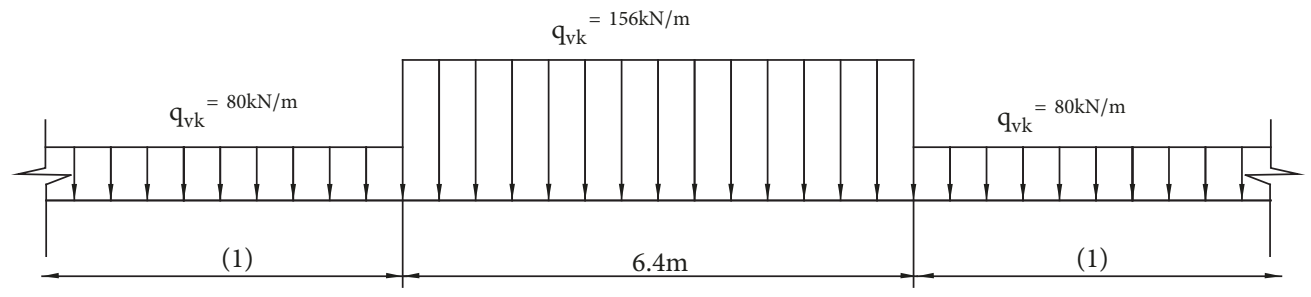

(1) No limitation

FIGURE 6: Load model and characteristic values for vertical train loads [5].

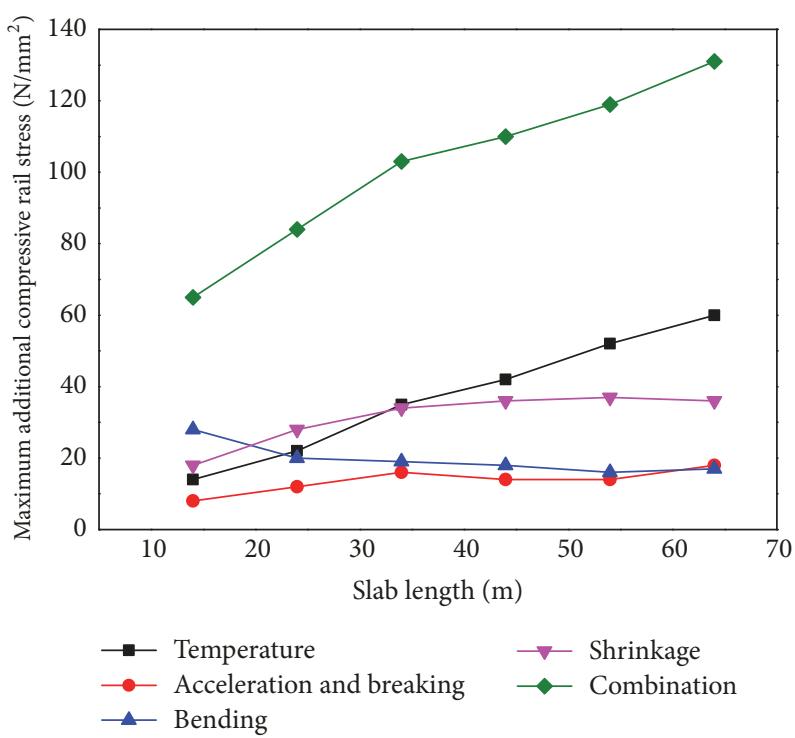

(a) Case $\mathrm{A}$

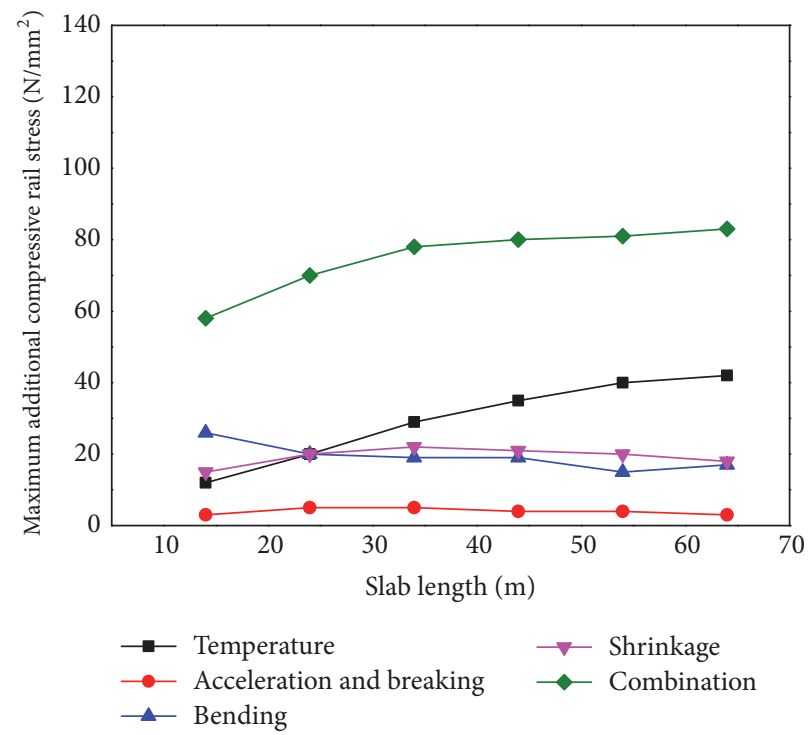

(b) Case B

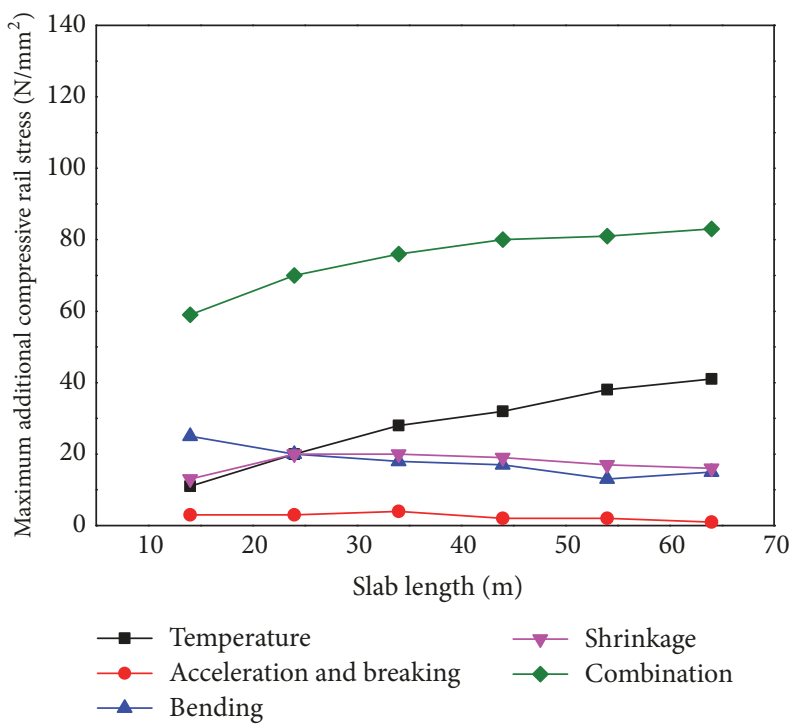

(c) Case C

FIGURE 7: Results of additional compressive rail stress with increasing slab length. 


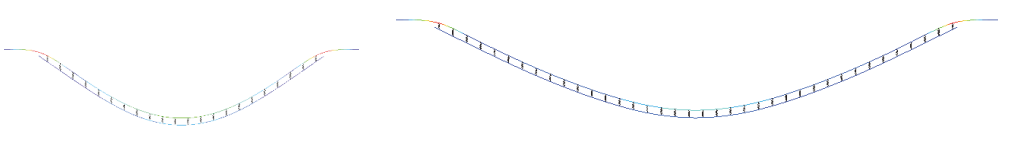

(a) Slab length $=14.5 \mathrm{~m}$

(b) Slab length $=24.5 \mathrm{~m}$

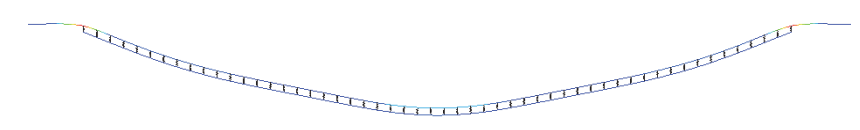

(c) Slab length $=34.5 \mathrm{~m}$

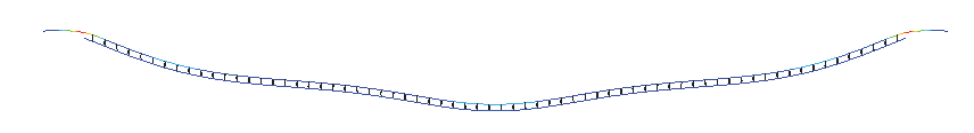

(d) Slab length $=44.5 \mathrm{~m}$

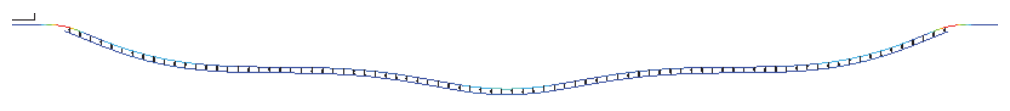

(e) Slab length $=54.5 \mathrm{~m}$

FIGURE 8: Bending behaviors of the rail and the slab.

displacement of the rail relative to its supporting structure. To simplify calculations, the stiffness is stated as a bilinear function of the rail displacement, as shown in Figure 4. The vertical track stiffness was estimated as $47 \mathrm{kN} / \mathrm{mm}$ based on the tests carried out by Pandrol [15].

The floating slab was connected to an isolator, and its rigid foundation was modeled by a spring element whose stiffness acts in a fixed direction. The isolator spring stiffness was identified by experimental tests [12]. Since the isolator is made of a rubber-based material, it shows hyperelastic and frequency-dependent behavior. In this study, the isolator's static stiffness was chosen for further analysis. The isolator's longitudinal stiffness value was taken from a previous study [12] and was used to simplify the behavior, as shown in Figure 5. The longitudinal isolator stiffness was calculated from these test values as $9 \mathrm{kN} / \mathrm{mm}$ and the vertical isolator stiffness as $10 \mathrm{kN} / \mathrm{mm}$ [12].

As mentioned in Research Methodology, the bed blocks were installed at both ends of the floating slab track. To simplify the simulation, each bed block was modeled using 11 spring elements over the entire $1 \mathrm{~m}$ length of the bed block. The stiffness values of the bed blocks in the longitudinal and vertical directions were taken to be the same as those of the isolator. As shown in Figure 3, an embankment was connected to the rail of the floating slab. To simulate continuity in the FST system, the stiffness of this area must be the same as the track stiffness. The stoppers restrict the slab movement in the longitudinal direction. In this study, an individual stopper was modeled by a spring with a longitudinal stiffness value of $1200 \mathrm{kN} / \mathrm{mm}$.

Several load cases can be considered in an FST system. This study considered the following four load cases: (1) changes in temperature, (2) breaking and acceleration, (3) bending, and (4) shrinkage. As the temperature changes, the slab expands and contracts. Assuming that the floating slab is subjected to uniform temperature changes, the temperature of the floating slab deviates from the reference temperature, as indicated in the UIC code. Breaking and acceleration forces applied at the top of the rail are considered to be distributed evenly over the length. These loads were chosen from the UIC code [11] as an acceleration force of $33 \mathrm{kN} / \mathrm{m}$ per track over a load length less than $33 \mathrm{~m}$ and a breaking force of $20 \mathrm{kN} / \mathrm{m}$ per track over a load length less than $400 \mathrm{~m}$. The results of the acceleration and breaking forces were compared to each other, and the maximum values were chosen for the final analysis. Vertical train loads produce bending of the floating slab, leading to rotation of the end sections and vertical displacement of the upper edge of the floating slab end. According to railroad-bridge longitudinal interaction analysis guidelines in Korea [5], the load arrangement and the characteristic values for vertical train loads were taken to be those shown in Figure 6. Finally, concrete shrinkage was also considered in this study. Shrinkage is not included in the UIC code [11], but in this study shrinkage is an important contributor to the mechanical properties of a concrete slab. It is necessary to include these parameters in the FST model. There are many prediction models for shrinkage in hardened concrete, such as ACI 209R-92, Bazant-Baweja B3, CEB MC90-99, and GL2000 [16-20]. This study adopts the CEB model [19]. The total strain due to shrinkage can be calculated as the sum of shrinkage strain and the product of compliance with stress [16]. According to the CEB model, the total shrinkage of concrete $\varepsilon_{s h}\left(t, t_{c}\right)$ may be calculated as

$$
\varepsilon_{s h}\left(t, t_{c}\right)=\varepsilon_{c a s}(t)+\varepsilon_{c d s}\left(t, t_{c}\right)
$$

where $\varepsilon_{\text {cas }}(t)$ is the autogenous shrinkage component and $\varepsilon_{c d s}\left(t, t_{c}\right)$ is the drying shrinkage after 1 year. A detailed expression of (1) is available from the ACI [16].

In this study, finite element analysis was chosen to solve the problem; for this reason, the effect of shrinkage was converted to a thermal problem by the effective modulus method. 


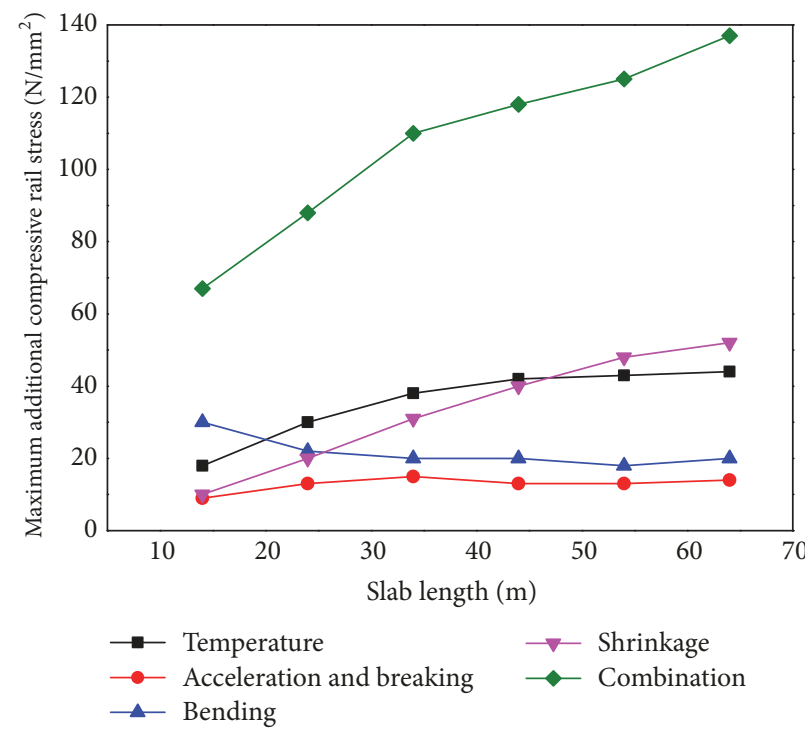

(a) Case $\mathrm{A}$

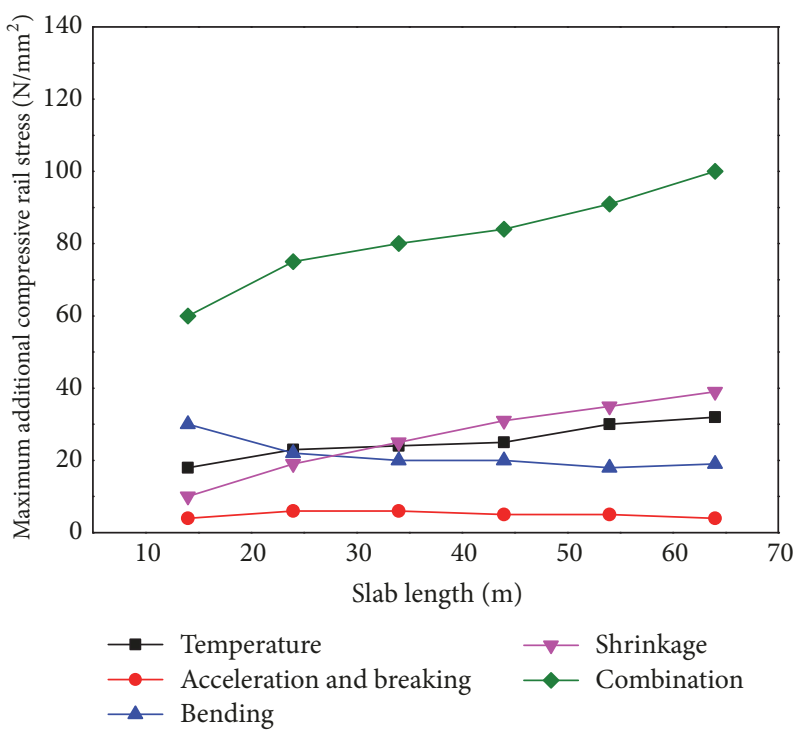

(b) Case B

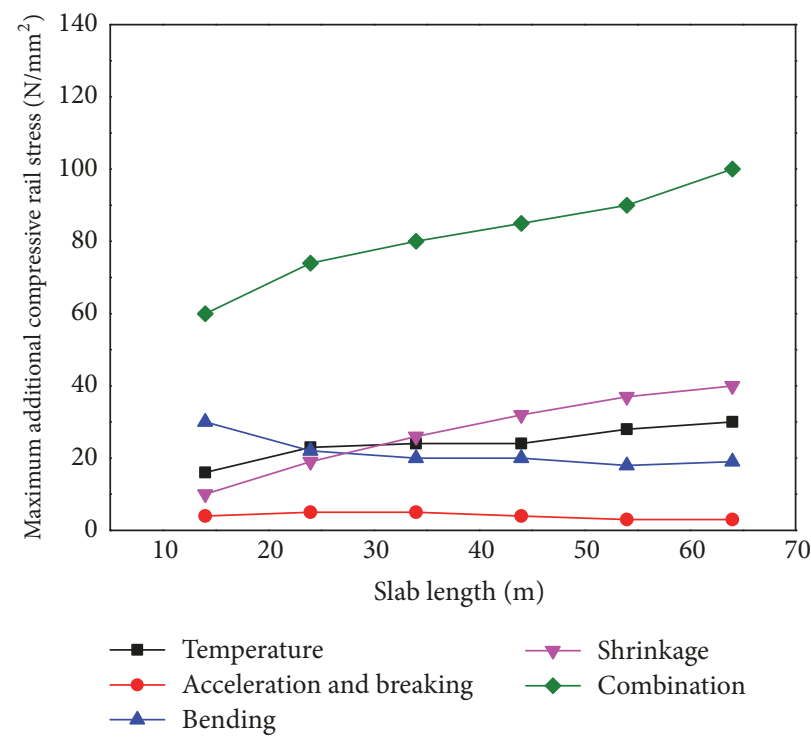

(c) Case C

FIgURE 9: Results of additional tensile rail stress with increasing slab length.

By this method, temperature changes $(\Delta T)$ were applied to the FST system to simulate shrinkage. The temperature changes can be estimated from the total strain $\varepsilon_{s h}\left(t, t_{c}\right)$ due to the shrinkage of the FST and were calculated to be âĂ $\breve{S} 255$ $\mu \varepsilon$, which can be converted into a temperature of âĂ $\breve{S} 21.25^{\circ} \mathrm{C}$. In finite element analysis, material properties must be given to each structural element. The element material properties of the rail are given in Table 1.

\section{Numerical Results and Discussions}

Finite element analysis of a standard FST was performed to understand the interaction behaviors of the FST system. The selected results of this study are the rail stresses, the slab tensile stresses and longitudinal displacement, and the
TABLE 1: Material constants.

\begin{tabular}{lcc}
\hline Material property & Rail & Floating slab \\
\hline $\begin{array}{l}\text { Young's modulus of } \\
\text { elasticity, E }(\mathrm{MPa})\end{array}$ & 200000 & 28000 \\
$\begin{array}{l}\text { Shear modulus, G } \\
(\mathrm{MPa})\end{array}$ & 79300 & 21000 \\
$\begin{array}{l}\text { Coefficient of thermal } \\
\text { expansion } \alpha\left(/{ }^{\circ} \mathrm{C}\right)\end{array}$ & $1.2 \times 10^{-5}$ & $1.2 \times 10^{-5}$ \\
Poisson's ratio & 0.3 & 0.2 \\
\hline
\end{tabular}

stoppers' longitudinal displacements. Figure 7 (a) shows the maximum additional compressive rail stress in Case A (with no stoppers). As the slab length increases, the overall rail 


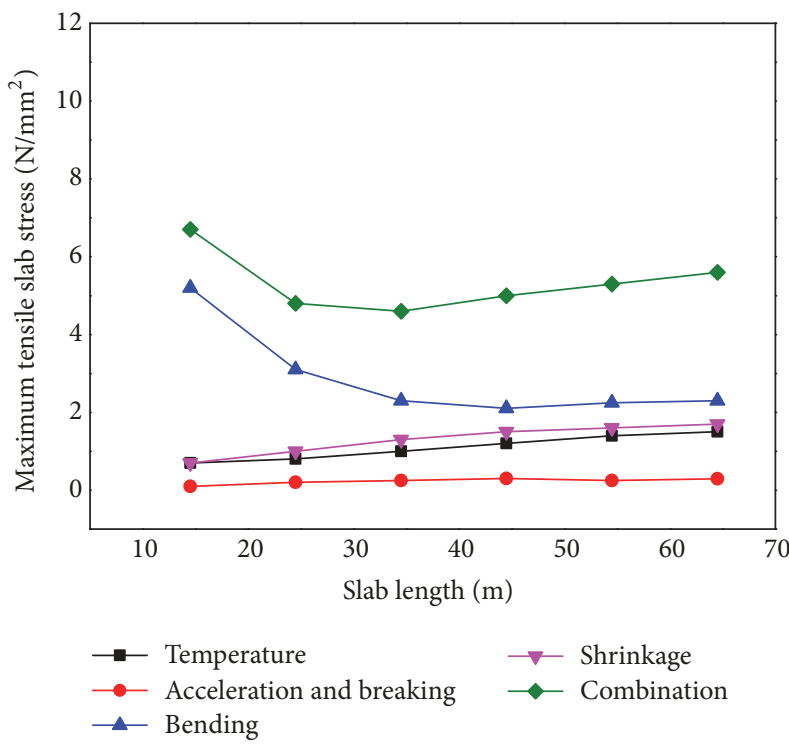

(a) Case $\mathrm{A}$

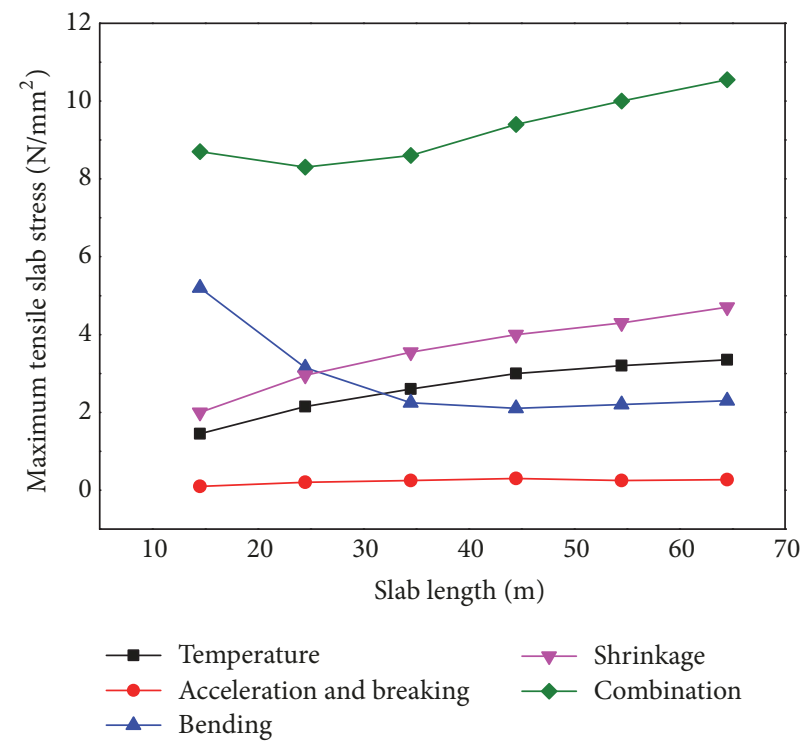

(b) Case B

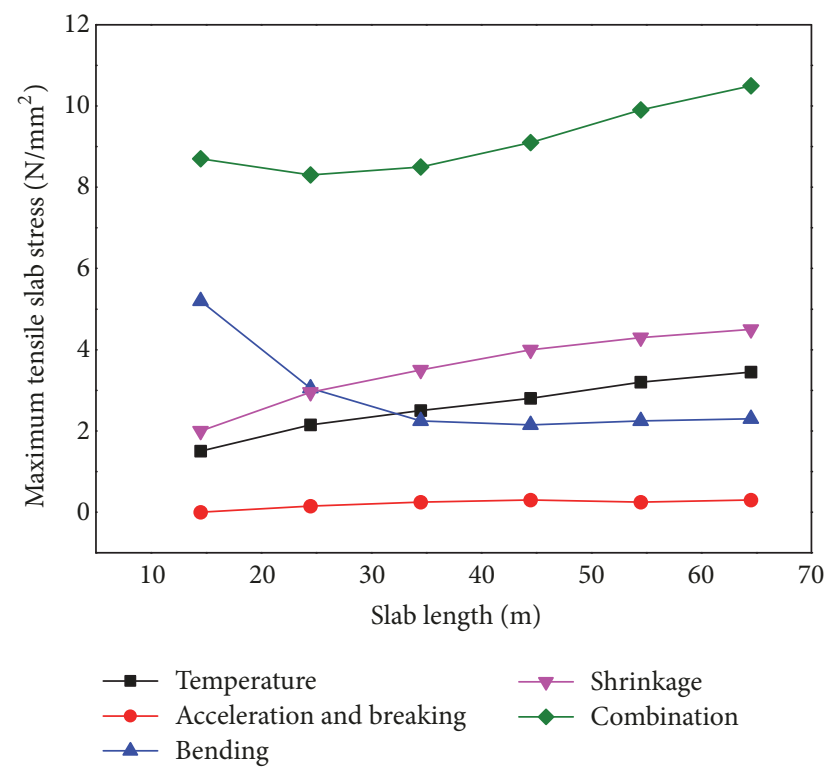

(c) Case C

FIGURE 10: Results of additional tensile slab stress with increasing slab length.

stress has a similar growth rate to the stress due to changes in temperature; the stresses due to other loads do not show any consistent trends. The deformed configuration of the FST due to bending is shown in Figure 8. The maximum rail stresses due to the FST bending always occur at the transition between the embankments and the floating slab track. This can be explained by the sudden change in stiffness from the embankment to the isolator. Figure 8 shows that the shape of the deformed track changes as the slab length changes. A shape with a single curve was observed in shorter slab lengths, while multiple curvatures were observed in longer slab lengths. This is a result of the bilinear behavior of the isolator stiffness. When the load increases to a limit value, the isolator stiffness value approaches infinity. At that time, it has a maximum reaction force and acts in the opposite direction, moving the slab in the upward direction. The variations in these values are small compared to the permissible maximum additional stresses in the CWR in the UIC code [11], indicating that the contributions of variation in maximum additional stresses are relatively nonsignificant. The total maximum additional rail stresses due to load combinations monotonically increase as the slab length increases. Actions due to changes in temperature are the major influencing factors in the combined maximum rail stress.

Figure 7(b) shows the maximum additional compressive rail stresses in Case B (with 2 stoppers), and Figure 7(c) shows 


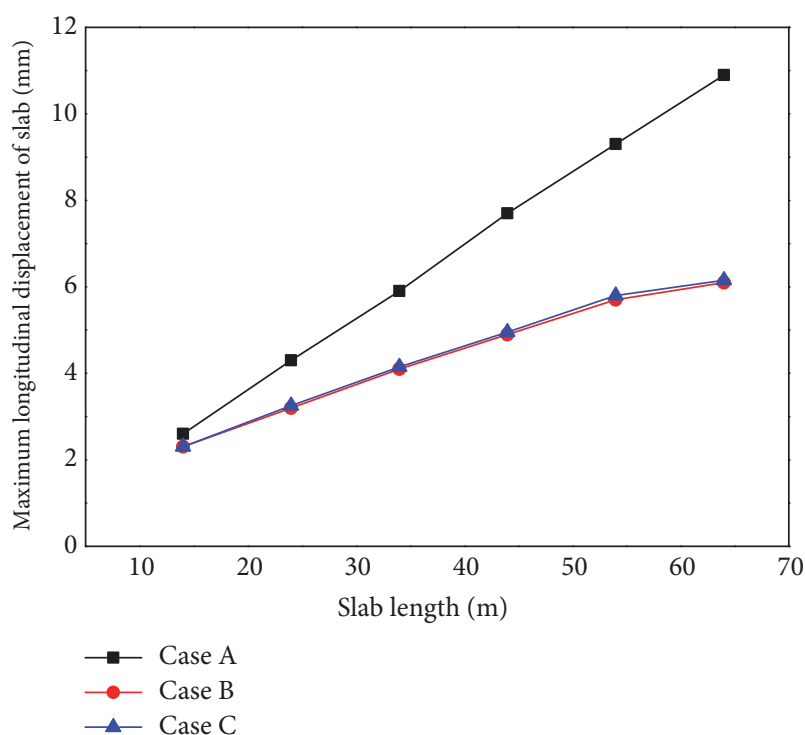

(a) Slab

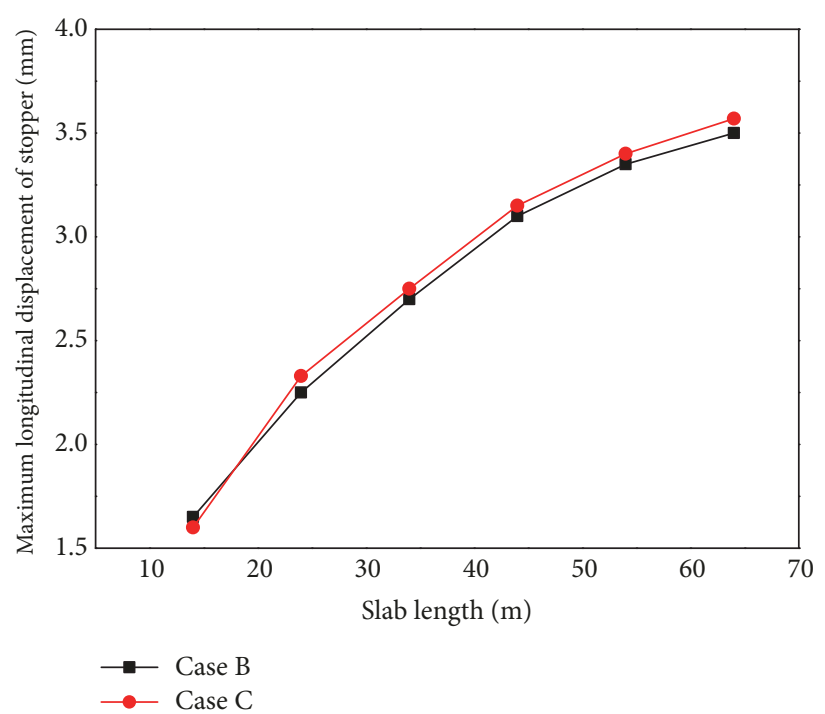

(b) Stopper

FIGURE 11: Longitudinal displacement.

the maximum additional compressive rail stresses in Case C (with 3 stoppers). The overall stress trends are similar to those of Case A (no stoppers); however, the magnitudes of the stresses in cases with stoppers (Cases B and C) are much lower compared to that with no stoppers (Case A). Specifically, the maximum stresses due to slab bending are the same for all cases because the stoppers do not restrict the vertical movement of the slab in a 2D FST system model; hence, additional compressive rail stresses have no effect on the bending. Particularly, in Cases B and C, the maximum stress values due to temperature and shrinkage loads have equal values. Because the center stopper in Case $\mathrm{C}$ is positioned at the axis of symmetry, the forces here due to temperature change and due to shrinkage act only in the longitudinal direction through the length of floating slab. Consequently, the stopper in the middle of the slab has no influence on the temperature and shrinkage forces. This observation indicates that the location of a stopper significantly affects the results of the analysis. Also, it is clear that the stresses increase as the slab length increases. In Case A (no stoppers), the maximum additional compressive rail stress increases rapidly over the allowable additional compressive rail stress with slab lengths over $30 \mathrm{~m}$. In Cases B and C, the maximum additional compressive rail stresses satisfy the permissible additional compressive rail stress requirement for all slab lengths. The cumulative additional tensile rail stresses are shown in Figure 9. Similar to the cumulative additional compressive rail stresses shown in Figure 7, the total combined stresses increase with slab length.

The maximum slab length is defined by the permissible additional stresses on the slab in the CWR. As mentioned in the Korean version of the UIC code [5], the maximum additional rail stress of UIC60 CWR is $92 \mathrm{~N} / \mathrm{mm}^{2}$ for additional compressive and tensile rail stresses. In Cases B and $\mathrm{C}$, the tensile rail stress reaches the maximum value at slab lengths of $54.5 \mathrm{~m}$, while the maximum length for Case $\mathrm{A}$ is $24.5 \mathrm{~m}$, a $30 \mathrm{~m}$ difference. This result highlights the importance of the stopper as a factor in the additional rail stress of an FST system.

Figure 10 shows the maximum tensile slab stresses with increasing slab lengths. The maximum stress due to bending occurs in the middle span of the floating slab and varies quite substantially with slab lengths between 14.5 and 34.5 $\mathrm{m}$. This can be explained as a result of the slab behavior, illustrated in Figure 8. Additional isolators are added when the slab length is increased; the slab is lifted under vertical loading when the slab length is between 14.5 and $34.5 \mathrm{~m}$. Length values exceeding this range will gradually increase stress. Figure 10(a) illustrates the increasing maximum tensile slab stresses due to shrinkage and temperature change; their values are nearly the same in Case A. However, Figures 10(b) and 10 (c) show rapidly increasing stress due to temperature when stoppers were added. This occurred because the stoppers act in the longitudinal direction, the same direction in which the temperature and shrinkage loads act. Figure 10 shows that the effects of acceleration and braking on the tensile slab stress are small because the load is applied to the rail along the track direction, not directly to the slab. Figure 10 also illustrates the cumulative tensile slab stress, which, in contrast to the cumulative tensile rail stress, is lower when there are no stoppers (Case A) than when stoppers are present (Cases B and C).

Figure 11(a) shows the maximum longitudinal displacement of the slab. In Figure 11(a), the slab displacement in Case A increases more quickly than in the other cases, which again illustrates the significant influence of stoppers on longitudinal displacement. When stoppers are installed, the maximum longitudinal displacement increases with an increase in slab length, as can be inferred from the results for Cases B and $\mathrm{C}$. With the exception of acceleration and breaking 


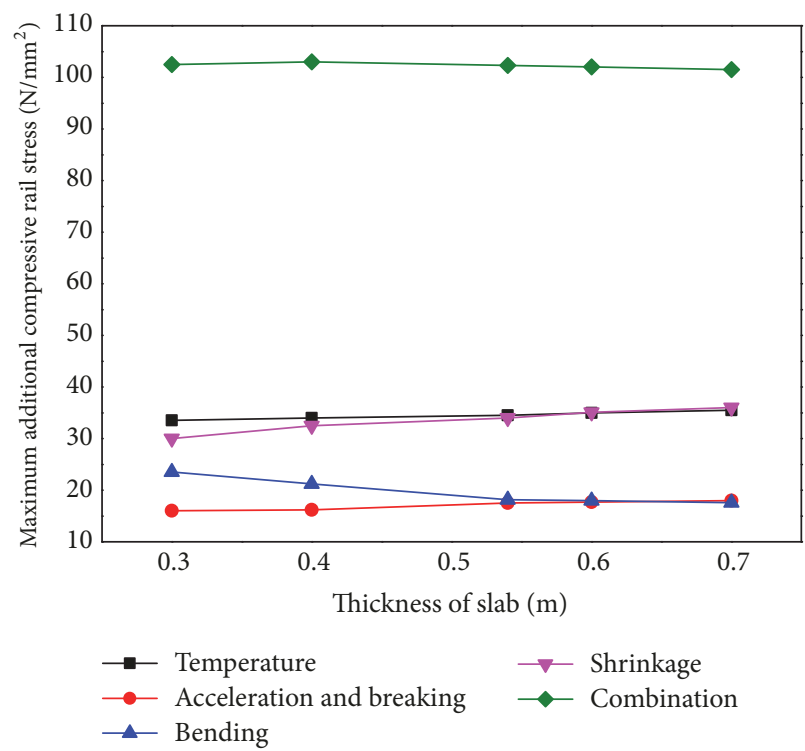

(a) Case $\mathrm{A}$

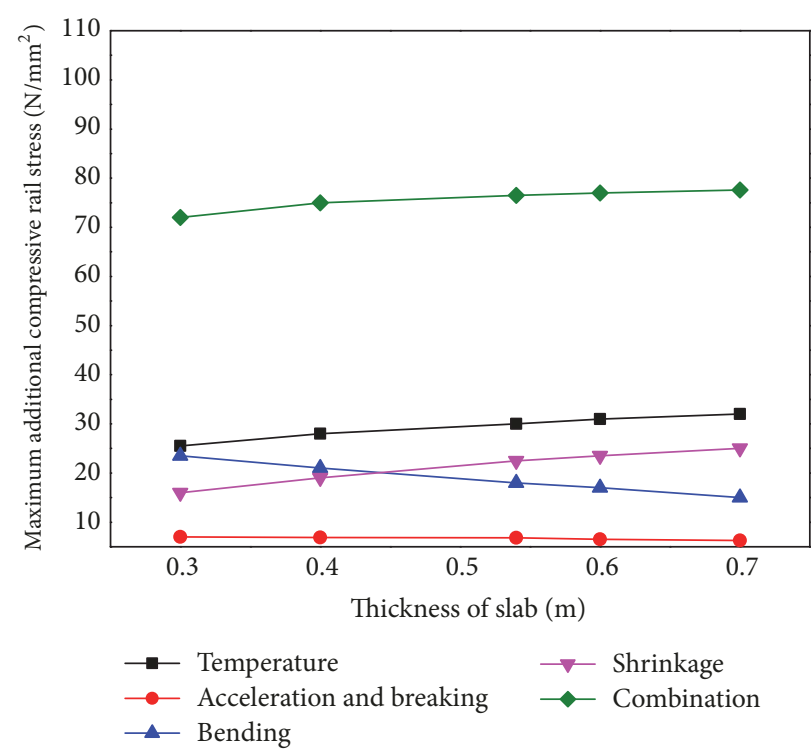

(b) Case B

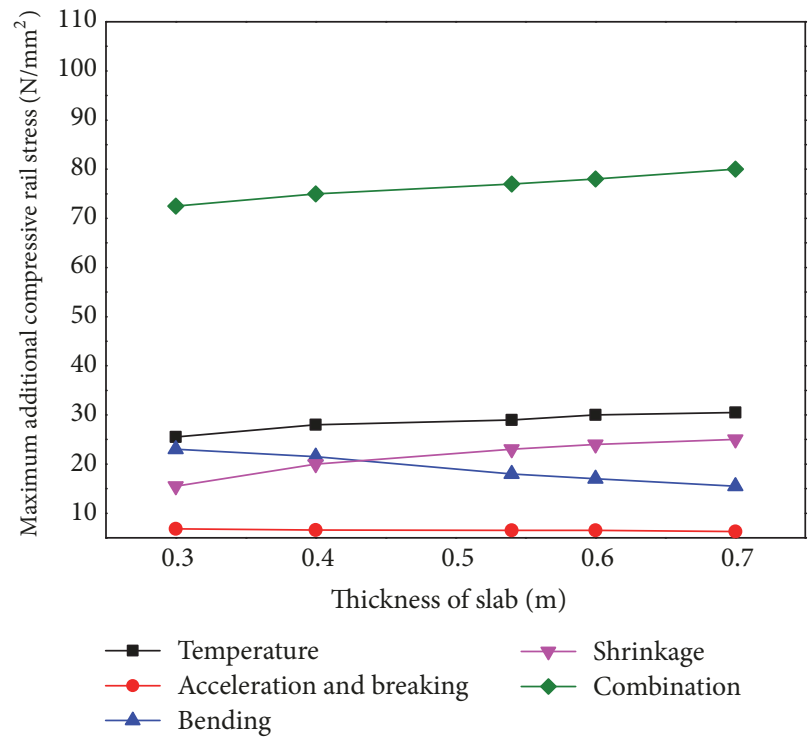

(c) Case C

FIGURE 12: Results of additional compressive rail stress with increasing slab thickness.

loading, the position of a stopper in the mid-span region has no influence on the rail stresses and longitudinal slab displacement. Figure 11(b) shows the maximum longitudinal displacement of the stopper. As the slab length increases, the maximum longitudinal displacement of both the slab and stopper increases in all three cases. The maximum longitudinal displacement of the stopper increases as the slab length increases.

The maximum additional compressive rail stresses with increasing slab thickness are shown in Figure 12. As can be seen in Figure 12(a), when no stoppers are used (Case A), the increases in maximum stress due to both temperature and acceleration and breaking are small when the slab thickness increases. Under vertical loading, the compressive rail stress has an inverse ratio to slab thickness, a trivially obvious result. Compressive rail stress due to shrinkage increases with slab thickness. The total additional compressive rail stress of a $0.6 \mathrm{~m}$ thick slab in Case A is $92.17 \mathrm{~N} / \mathrm{mm}^{2}$, over the maximum permissible additional stress from the UIC code [11]. The overall trends in Figures 12(b) and 12(c) are the same as for Case A but with lower magnitudes. The additional compressive stress trends in Cases B and C can be seen more clearly than in Case A, especially those due to temperature changes. The cumulative loads in Figure 12 clearly show the beneficial effect of stoppers in an FST system with varying slab thicknesses. A reasonable slab thickness should be chosen and combined with other appropriately chosen variables such as slab length and isolator stiffness. The maximum additional tensile rail stresses with increasing slab thickness are plotted in Figure 13. In general, the trends in this case are 


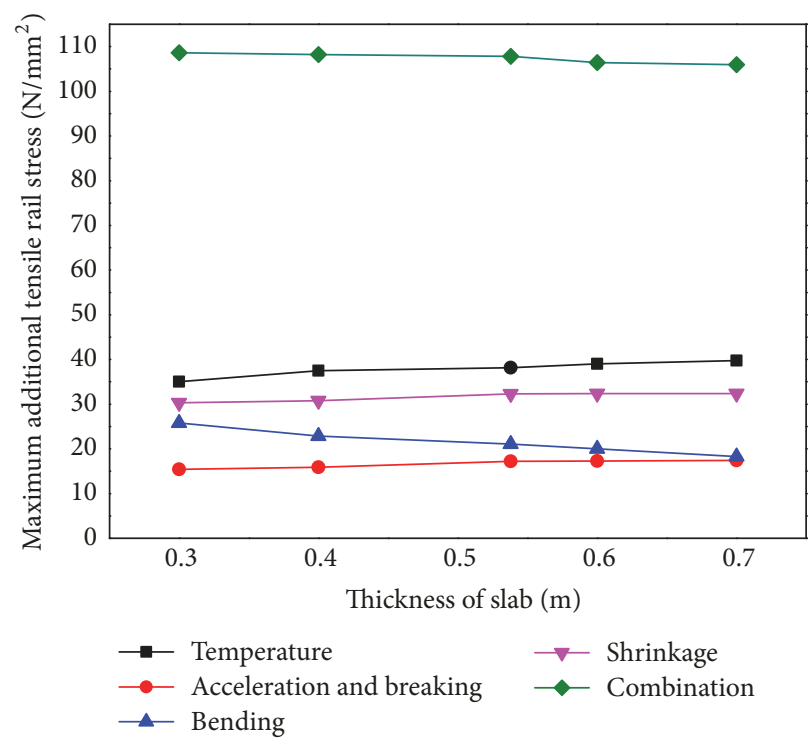

(a) Case $\mathrm{A}$

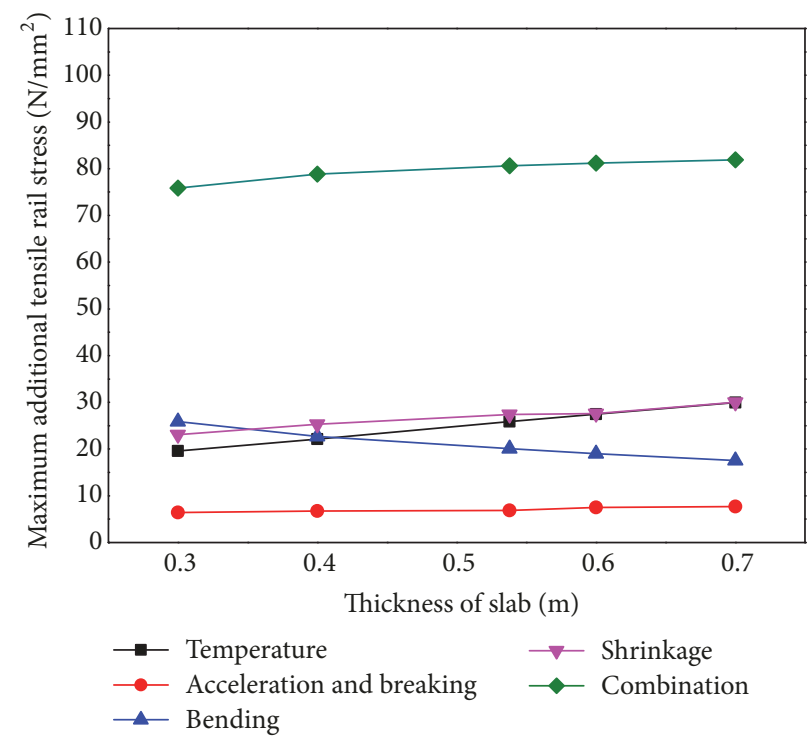

(b) Case B

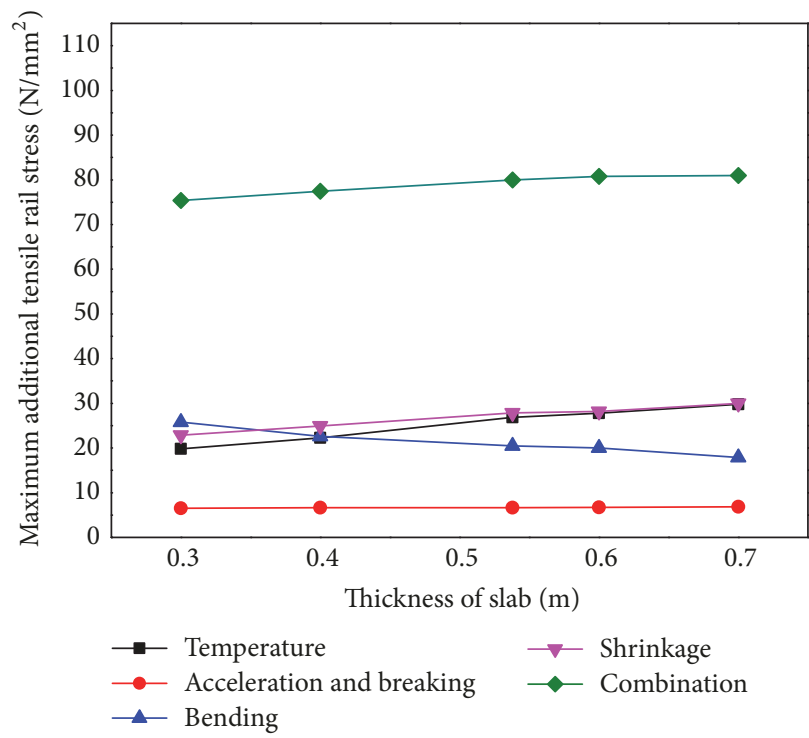

(c) Case C

FIGURE 13: Results of additional tensile rail stress with increasing slab thickness.

the same as those for maximum additional compressive rail stresses, but the tensile stresses for Cases B and C increase faster with increasing slab thickness than for Case A. This is again explained as an effect of the stoppers, which restrict the longitudinal displacement of the slab, causing the stresses to increase faster with increasing slab thickness. Figure 14 shows the maximum tensile slab stress with increasing slab thickness. In Case A, the concrete flexural stiffness increases as the slab thickness increases, which resists the generation of tensile slab stress over the entire slab. Thus, the stress decreases with increasing slab thickness for all loading types. These decreasing stresses also occur in Cases B and C. The cumulative maximum tensile slab stress is significantly lower when no stoppers are installed (Case A) than in the other cases in which they are used (Cases B and C).

Figure 15 shows the maximum additional compressive rail stress with changes in the isolator stiffness. The main contributor to the cumulative load combination is the bending load, which is an effect of the behavior of isolator stiffness, which only acts in the vertical direction in an FST system. In this simulation, loads due to temperature, shrinkage, and acceleration and breaking act only in the longitudinal direction and do not cause stress in the rail. The three stopper cases (Cases $A, B$, and C) show the same stress trend but with different magnitudes. Figure 16 shows the maximum additional tensile rail stress with changing isolator stiffness. For the same 


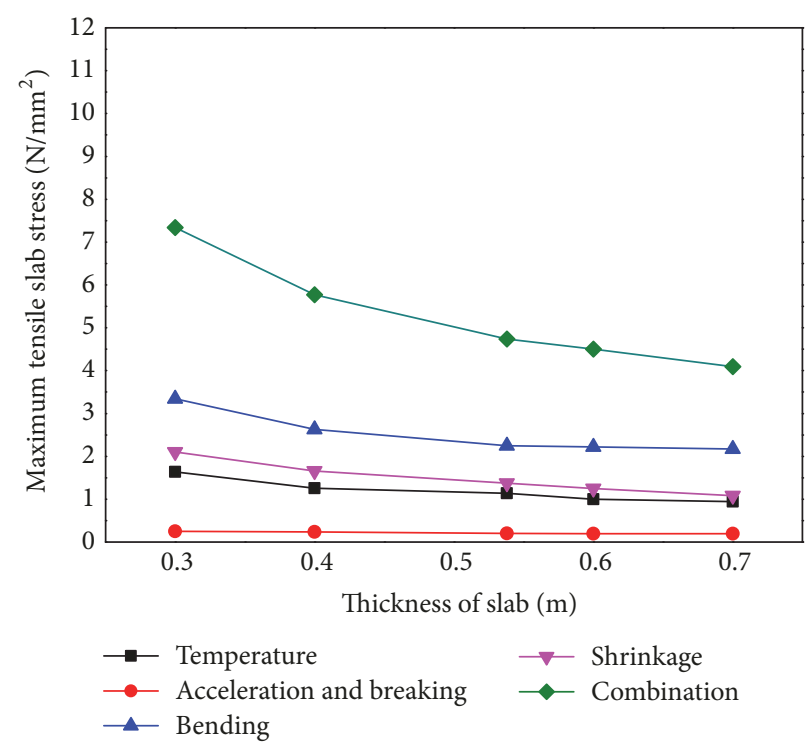

(a) Case $\mathrm{A}$

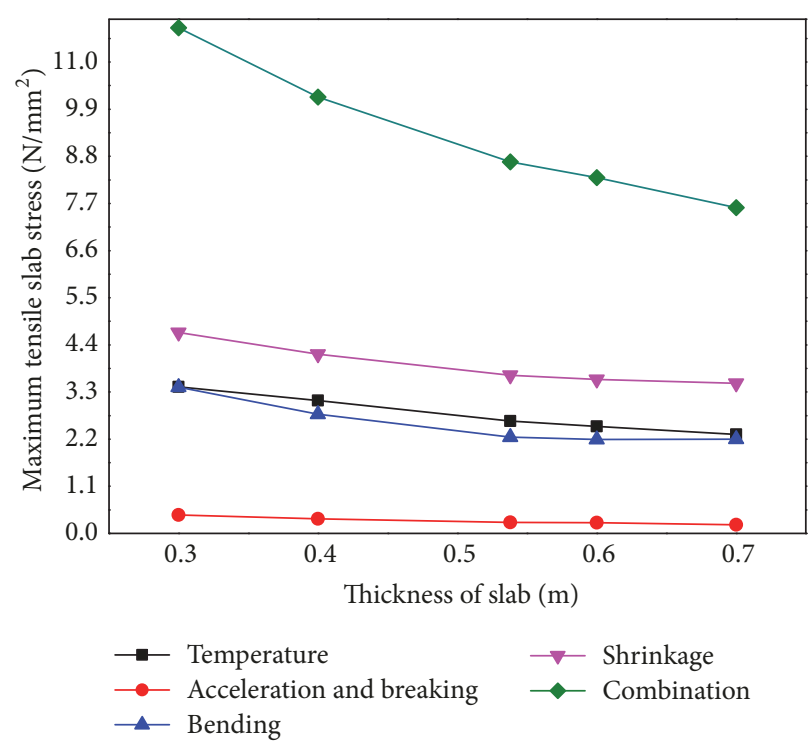

(b) Case B

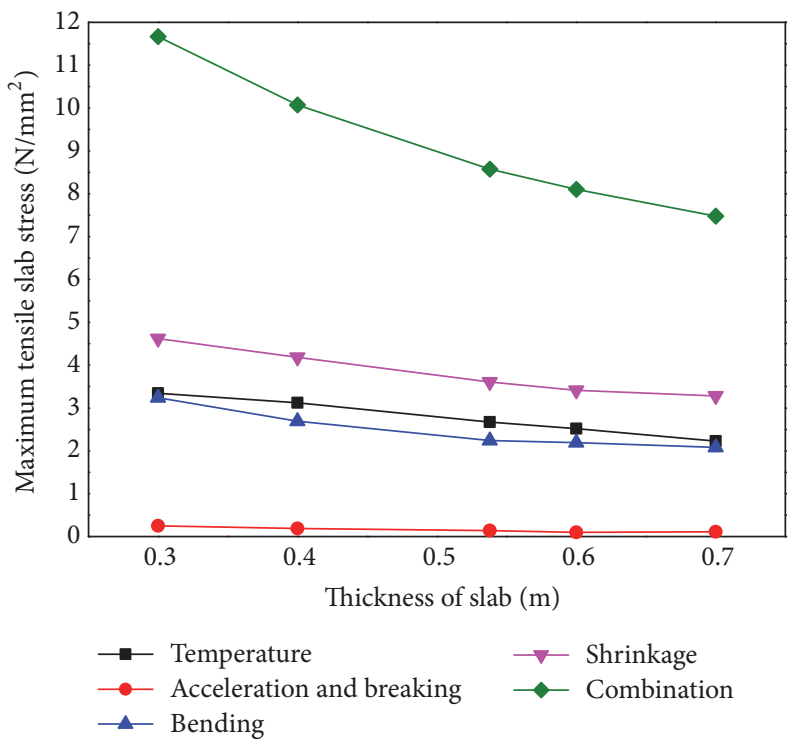

(c) Case C

FIGURE 14: Results of tensile slab stress with increasing slab thickness.

reasons as the compressive rail stress, the maximum tensile rail stresses decrease as the isolator stiffness increases. Here, the only factor causing changes in the stress is the slab bending. The cumulative load combinations in Figure 16 show only a small difference between Cases B and C due to the stopper placement but show much higher stresses when no stoppers are installed, as in Case A. Figure 17 shows the maximum tensile slab stress with changing isolator stiffness. The tensile slab stress decreases as the isolator stiffness increases. The stress shows the same trends in all three cases, but the magnitude of the cumulative load combination stresses in Cases B and C is larger than that of Case A. This result is the opposite of that of rail stress because of the installation of stoppers.

In general, the results show that temperature change, bending, and shrinkage result in greater stresses on the FST system than acceleration and breaking. In almost all cases, the stresses due to acceleration and breaking have very small values. Thus, these behaviors have no significant impact on the load combination case.

\section{Formula for Maximum Additional Rail Stress}

The maximum additional rail stress of an FST system is the most important factor in the design of a CWR system, since the slab length is limited based on the maximum additional rail stress; however, modeling and analysis of an FST system with many parameters such as slab length and thickness and isolator stiffness are time-consuming. Thus, knowledge of the relationships between the parameters is needed to reduce the 


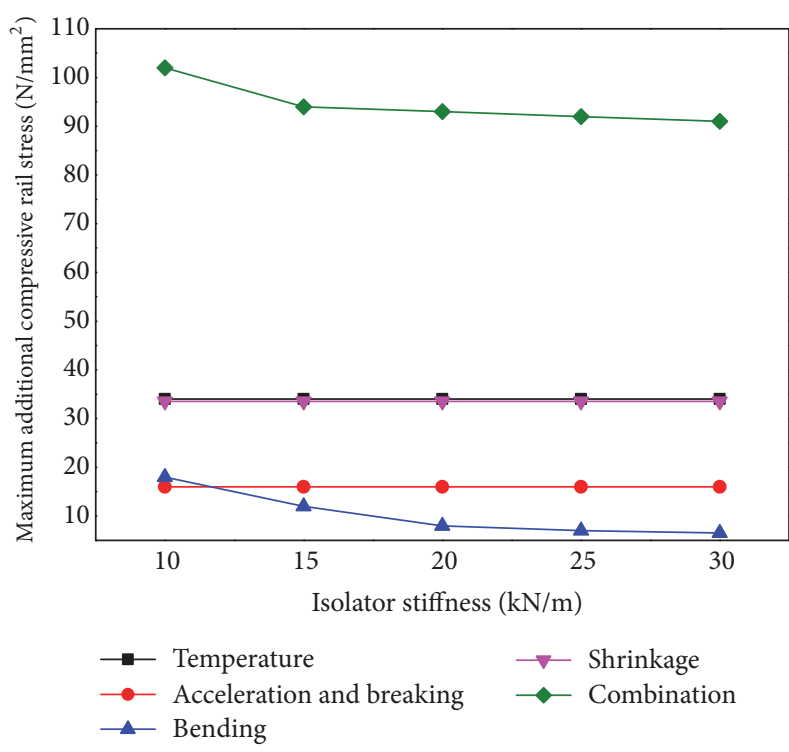

(a) Case $\mathrm{A}$

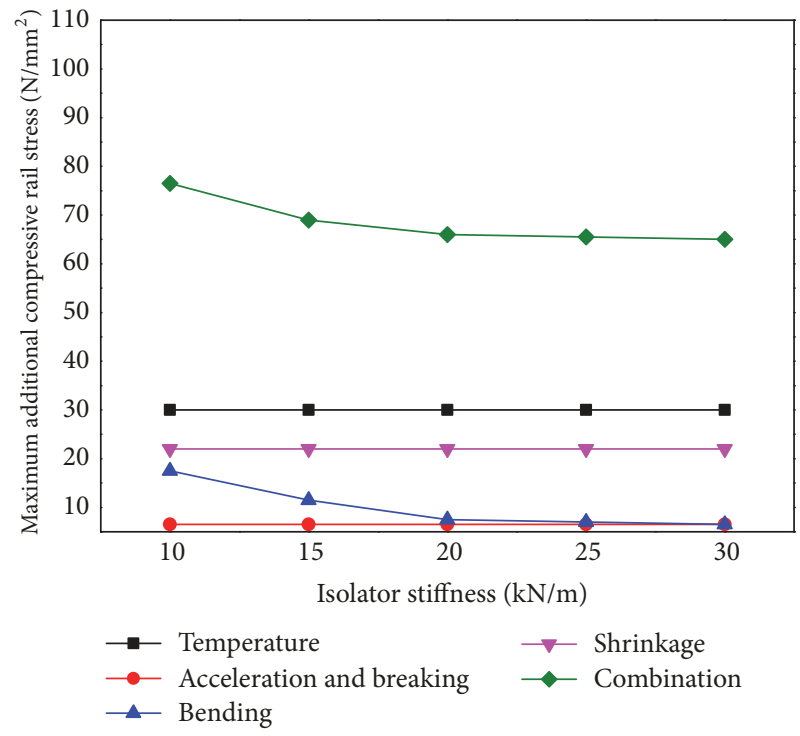

(b) Case B

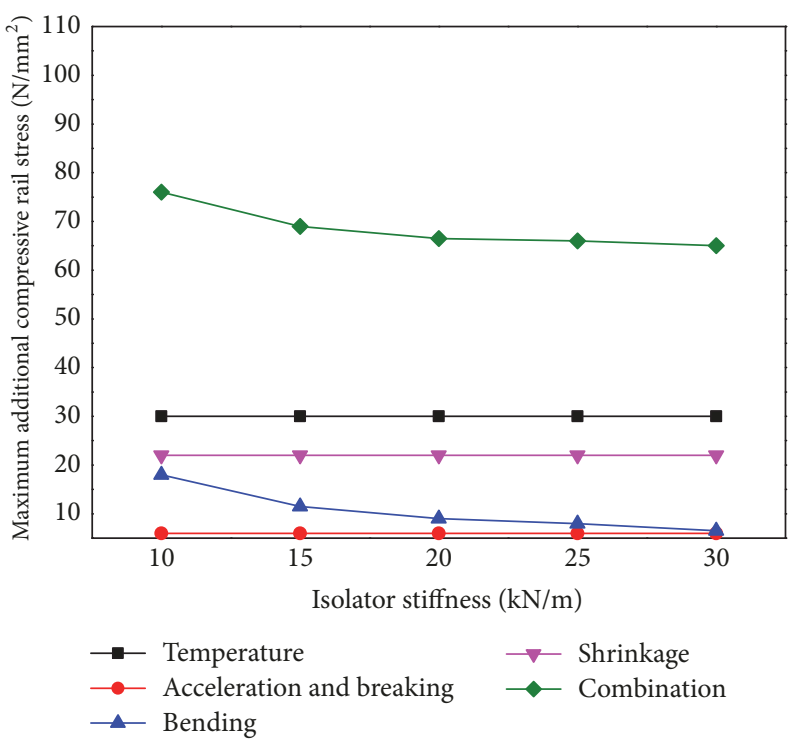

(c) Case C

FIGURE 15: Results of compressive rail stress with increasing isolator stiffness.

calculation volume. The purpose of this section is to find that relationship based on previously analyzed data.

This study proposed a formula for maximum additional rail stress based on a nonlinear regression analysis of the interaction analysis results. The formula is proposed to confirm the sensitivities of each parameter. In this study, the interaction analysis was carried out up to the maximum slab length for FSTs. Thus, the applicable range for the slab length was chosen as 14.5 to $54.5 \mathrm{~m}$. In the same manner, the applicable slab thickness range was 0.3 to $0.7 \mathrm{~m}$. The isolator stiffness was fixed at $9 \mathrm{kN} / \mathrm{mm}$. Young's modulus of the material used to make the slab track is between 20 and 35 GPa.

Within the chosen applicable ranges, the additional compressive rail stress is chosen to be a dependent variable, and the slab length and thickness are chosen as two independent variables; the formula obtained based on a nonlinear regression analysis was

$$
\sigma_{c}=a+b L+c L^{2}+d L^{3}+e L^{4}+\frac{f}{t}+\frac{g}{t^{2}}+\frac{h}{t^{3}}+\frac{i}{t^{4}}
$$

where $\sigma_{\mathrm{c}}$ is the additional compressive rail stress, $L$ is the slab length, $t$ is the slab thickness, and the coefficients $a, b, c, d, e$, $f, g, h$, and $i$ have the values shown in Table 2 .

In the same manner, the formula for additional tensile rail stress based on interaction analysis is proposed to be

$$
\begin{aligned}
\sigma_{t}= & a+b L+c L^{2}+d L^{3}+e L^{4}+f L^{5}+g \ln (t) \\
& +h \ln (t)^{2}+i \ln (t)^{3}
\end{aligned}
$$




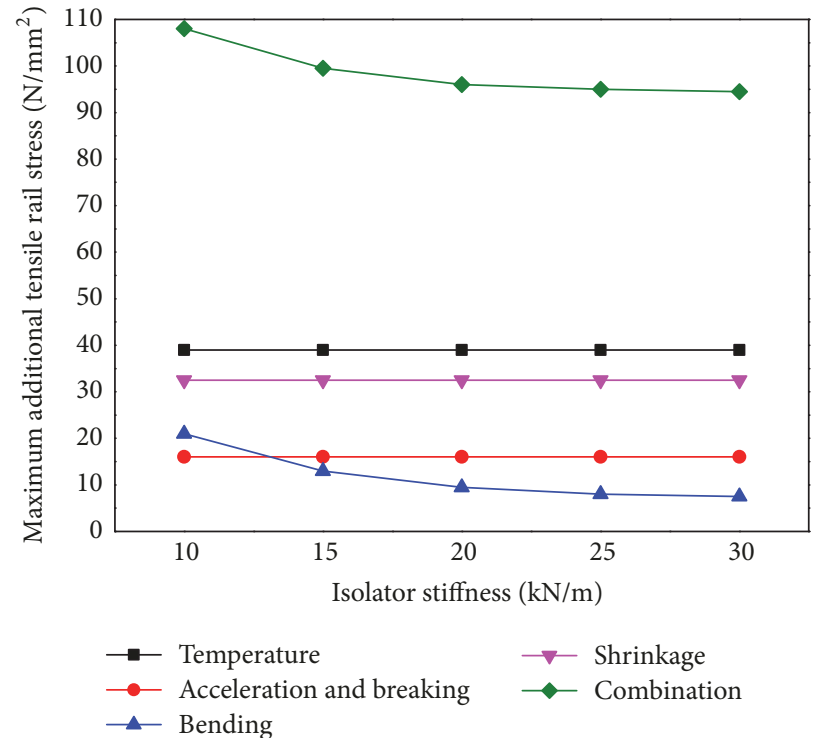

(a) Case $\mathrm{A}$

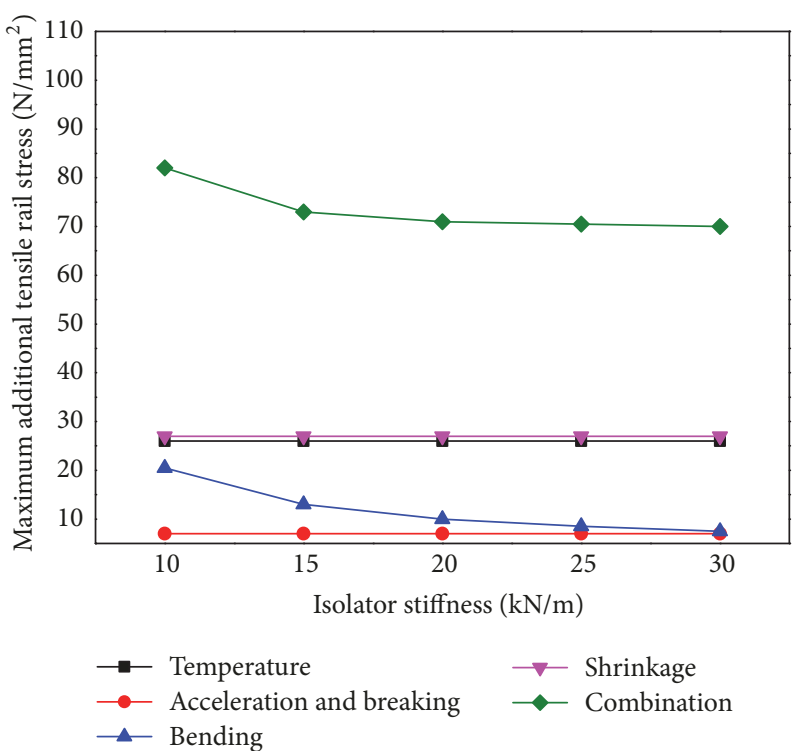

(b) Case B

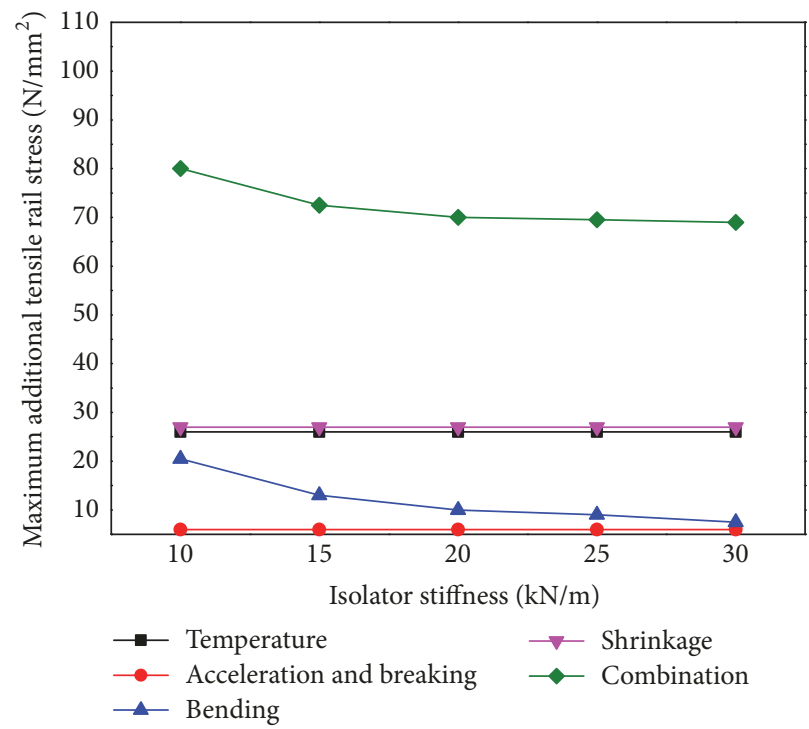

(c) Case C

FIGURE 16: Results of tensile rail stress with increasing isolator stiffness.

where $\sigma_{\mathrm{t}}$ is the additional tensile rail stress, $L$ is the slab track length, $t$ is the slab track thickness, and the coefficients $a, b$, $c, d, e, f, g, h$, and $i$ have the values shown in Table 2 .

The additional rail stresses from the proposed formula are compared with those obtained from finite element analysis in the applicable slab length and thickness ranges, as shown in Figures 18 and 19, respectively. These figures plot the ratio of the additional rail stresses obtained from the interaction analysis to those from the proposed formula, showing that the additional rail stress from the design equation is always greater than the finite element results. Within the applicable range of an FST system, the formula always produces additional rail stresses that are conservative by up to $10 \%$; because of this, the proposed formula is expected to become a safety margin in the design of an FST.

\section{Conclusions}

This paper examines the behavior of an FST by means of a track-slab-isolator interaction analysis. Parametric studies were conducted on the geometry and material properties of an FST to investigate the key behaviors of an FST. Many FST system cases were modeled and analyzed from a standard case to investigate the response behavior of an FST. The results from the analysis were used in a proposed formula for additional rail stress of an FST 


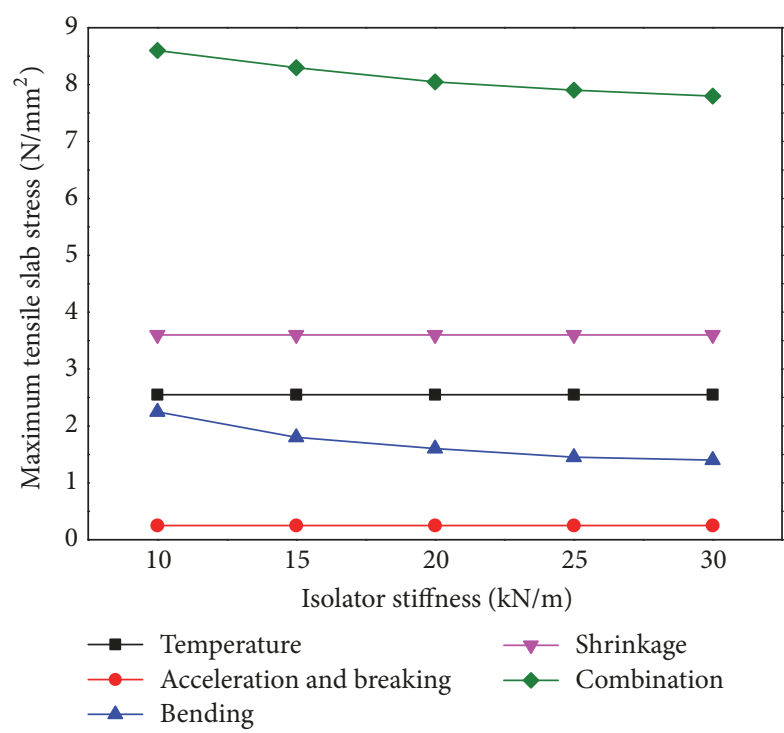

(a) Case $\mathrm{A}$

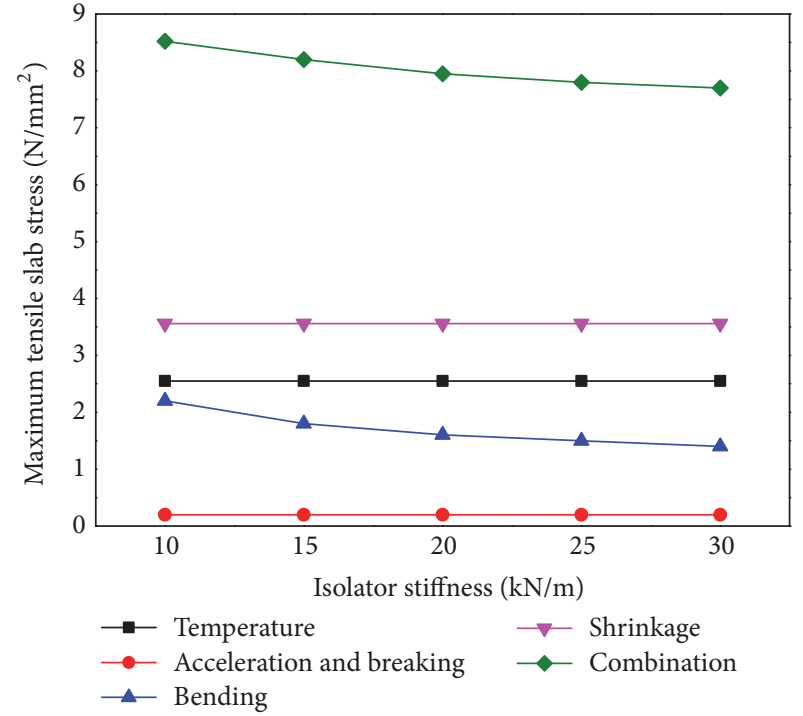

(b) Case B

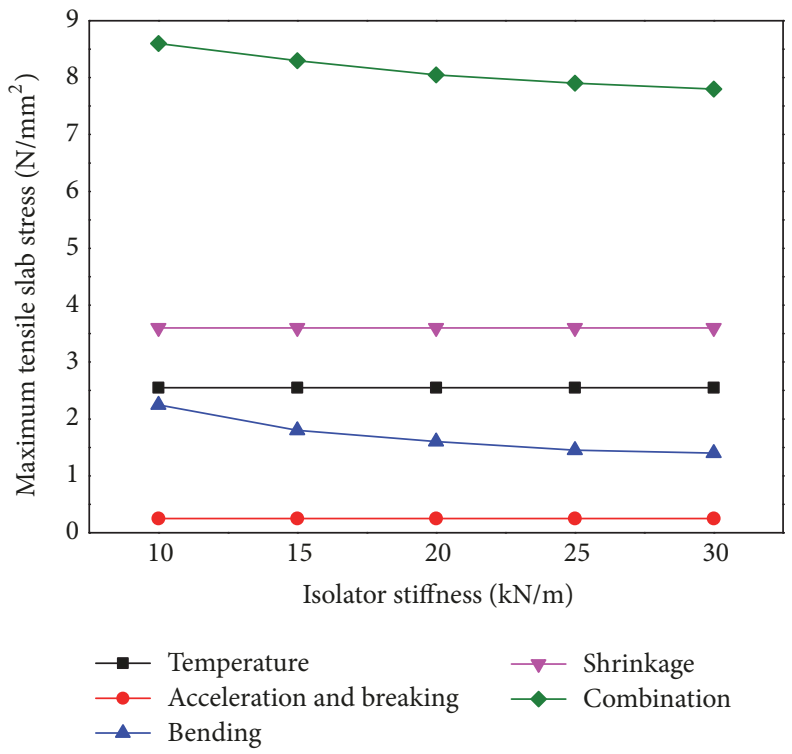

(c) Case C

FIGURE 17: Results of tensile slab stress with increasing isolator stiffness.

TABLE 2: Coefficients in the rail stress formula.

\begin{tabular}{lccc}
\hline \multicolumn{2}{l}{ Additional compressive rail stress } & \multicolumn{2}{c}{ Additional tensile rail stress } \\
\hline Coefficient & Value & Coefficient & Value \\
\hline $\mathrm{a}$ & -32.494 & $\mathrm{a}$ & 11.952 \\
\hline $\mathrm{b}$ & -1.659 & $\mathrm{~b}$ & 6.233 \\
\hline $\mathrm{c}$ & $-3.12 \times 10^{-3}$ & $\mathrm{c}$ & -0.225 \\
\hline $\mathrm{d}$ & $7.389 \times 10^{-4}$ & $\mathrm{~d}$ & $4.36 \times 10^{-3}$ \\
\hline $\mathrm{e}$ & $-7.333 \times 10^{-6}$ & $\mathrm{e}$ & $-4.3 \times 10^{-5}$ \\
\hline $\mathrm{f}$ & -17.448 & $\mathrm{f}$ & $1.824 \times 10^{-7}$ \\
\hline $\mathrm{g}$ & 15.753 & $\mathrm{~g}$ & 3.416 \\
\hline $\mathrm{h}$ & -5.057 & $\mathrm{~h}$ & -3.56 \\
\hline $\mathrm{i}$ & 0.581 & $\mathrm{i}$ & -0.521 \\
\hline
\end{tabular}

system. The following conclusions were derived from the research.

The results of additional rail stresses demonstrate that temperature, bending, and shrinkage produce greater stresses on the FST system than acceleration and breaking. It has been shown that slab length is the most sensitive parameter influencing the additional rail stress; the maximum slab length for a standard FST is $54.5 \mathrm{~m}$ with stoppers and 24.5 $\mathrm{m}$ without stoppers, a significant difference. For this reason, stoppers should be used and carefully installed to optimize the overall function of the FST system.

Finally, the formula proposed for additional rail stress always produces results up to a $10 \%$ conservative safety margin, within the applicable parameter range of the FST system, and can be effectively used in the design phase. 


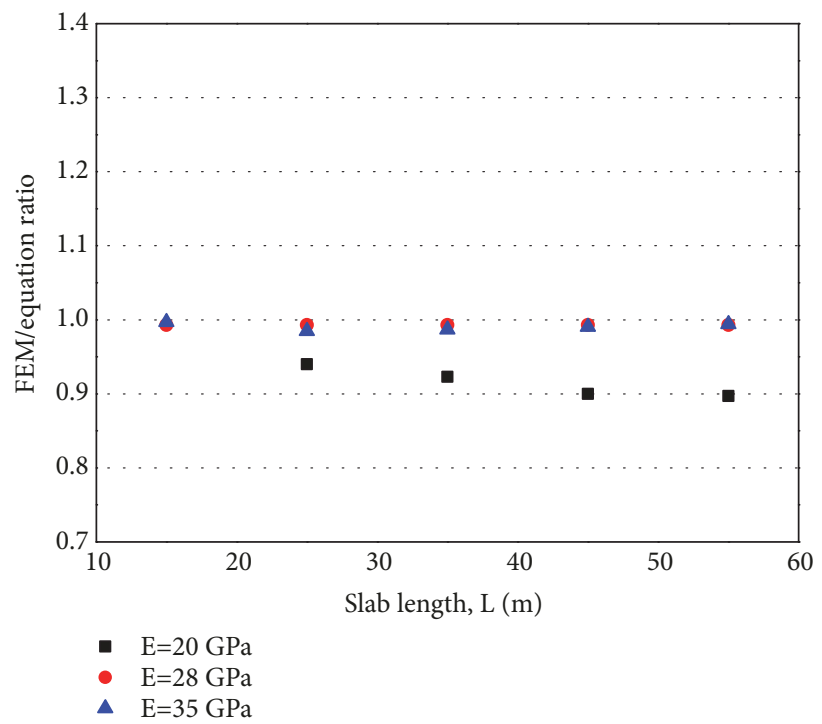

(a) Slab length

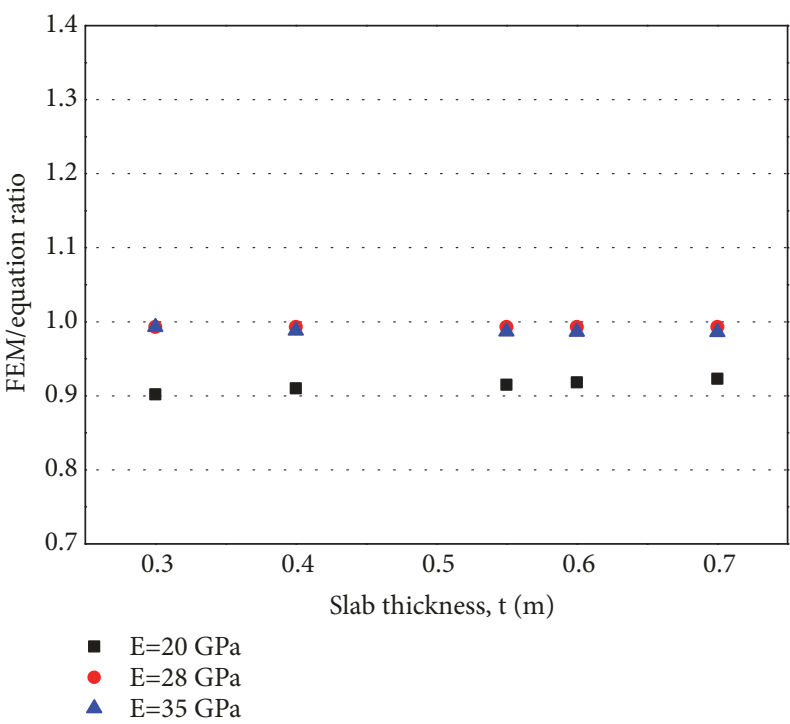

(b) Slab thickness

FIGURE 18: Additional compressive rail stress comparisons between the design equation and the FEM.

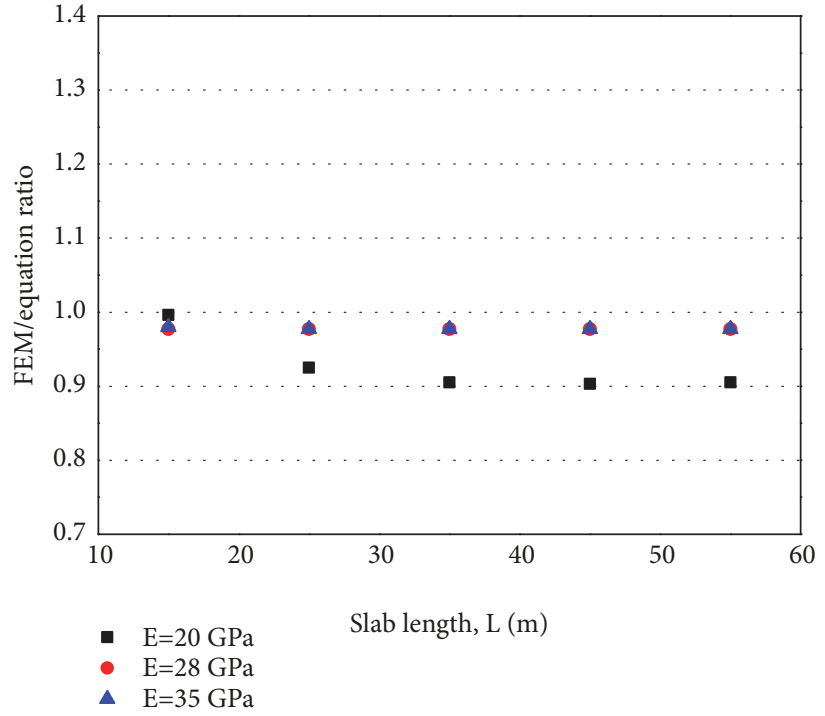

(a) Slab length

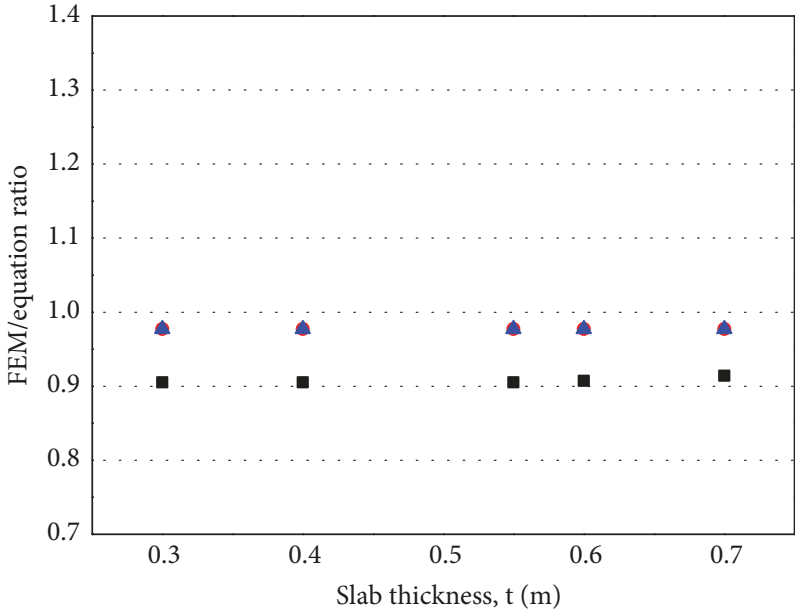

- $\mathrm{E}=20 \mathrm{GPa}$

- $\mathrm{E}=28 \mathrm{GPa}$

- $\mathrm{E}=35 \mathrm{GPa}$

FIGURE 19: Additional tensile rail stress comparisons between the design equation and the FEM.

\section{Data Availability}

The data used to support the findings of this study are available from the corresponding author upon request.

\section{Conflicts of Interest}

The authors declare that they have no conflicts of interest.

\section{Acknowledgments}

This study is a basic research project conducted with support from the National Research Foundation of Korea through government funds (Ministry of Science, ICT, and Future Planning, Republic of Korea). The project numbers are 2017R1A2B4010467 and 2017R1C1B1006732.

\section{References}

[1] J. T. Nelson, "Recent developments in ground-borne noise and vibration control," Journal of Sound and Vibration, vol. 193, no. 1, pp. 367-376, 1996.

[2] G. Lombaert, G. Degrande, B. Vanhauwere, B. Vandeborght, and S. François, "The control of ground-borne vibrations from railway traffic by means of continuous floating slabs," Journal of Sound and Vibration, vol. 297, no. 3-5, pp. 946-961, 2006. 
[3] W. D. Henn, "System comparison: ballasted track - slab track," Rail Engineering International, vol. 22, no. 2, 1993.

[4] D. N. Bilow and G. M. Randich, "Slab track for the next 100 years. Presented at the AREMA," in Proceedings of the 2000 Annual Conference, 2000.

[5] Korea Rail Network Authority, Guideline of Railway Design, 2011.

[6] P. Grootenhuis, "Floating track slab isolation for railways," Journal of Sound and Vibration, vol. 51, no. 3, pp. 443-448, 1977.

[7] S.-T. Yen and Y.-H. Lee, "Parameter identification and analysis of a slab track system using 3D ABAQUS program," Journal of Transportation Engineering, vol. 133, no. 5, pp. 288-297, 2007.

[8] G. Degrande, D. Clouteau, R. Othman et al., "A numerical model for ground-borne vibrations from underground railway traffic based on a periodic finite element-boundary element formulation," Journal of Sound and Vibration, vol. 293, no. 3-5, pp. 645-666, 2006.

[9] H. G. Wagner and A. Herrmann, "Floating slab track above ground for turnouts in tram lines," Noise and Vibration Mitigation for Rail Transportation Systems, vol. 99, pp. 86-93, 2008.

[10] J. Yuan, Y. Chang, Z. Meng, and L. Song, "Modal analysis and parameter assessment of floating slab track," in Proceedings of the 2nd International Conference on Transportation Engineering, ICTE 2009, pp. 3294-3299, July 2009.

[11] International Union of Railways, Track/Bridge Interaction. Recommendations for Calculations, CODE 774-3R, UIC, 2nd edition, 2001.

[12] Land Transport and Maritime R\&D Report, Development of Low Vibration Track (Floating Slab Track) And Technology for Improvement of Performance of Long-Span Bridges, 2011.

[13] Z. G. Li and T. X. Wu, "On vehicle/track impact at connection between a floating slab and ballasted track and floating slab track's effectiveness of force isolation," Vehicle System Dynamics, vol. 47, no. 5, pp. 513-531, 2009.

[14] ABAQUS Inc, ABAQUS/Standard User's Manual, ABAQUS Inc., Pawtucket, RI, USA, 2007.

[15] Pandrol, "Testing of in-line SFC on Rheda 2000 to KHSRC specification,” Tech. Rep. 46011-9, 2004.

[16] ACI Committee 209, 209.2R-08 Guide for Modeling and Calculating Shrinkage and Creep in Hardened Concrete, American Concrete Institute, 2008.

[17] Z. P. Bažant and S. Baweja, "Justification and refinements of model B3 for concrete creep and shrinkage 1. statistics and sensitivity," Materials and Structures, vol. 28, no. 7, pp. 415-430, 1995.

[18] Z. P. Bazant, "Criteria for rational prediction of creep and shrinkage of concrete," ACI Special Publications, vol. 194, pp. 237-260, 2000.

[19] C. F. M. Code, CEB-FIP Model Code for Concrete Structures, Euro-International Committe for Concrete, Bulletin, 1990.

[20] N. J. Gardner and M. J. Lockman, "Design provisions for drying shrinkage and creep of normal strength concrete," ACI Materials Journal, vol. 98, no. 2, pp. 159-167, 2001. 


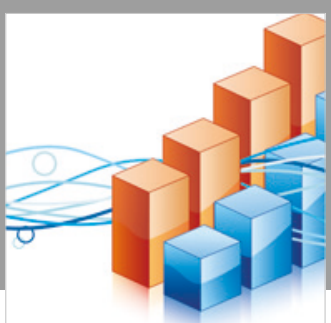

Advances in

Operations Research

\section{-n-m}
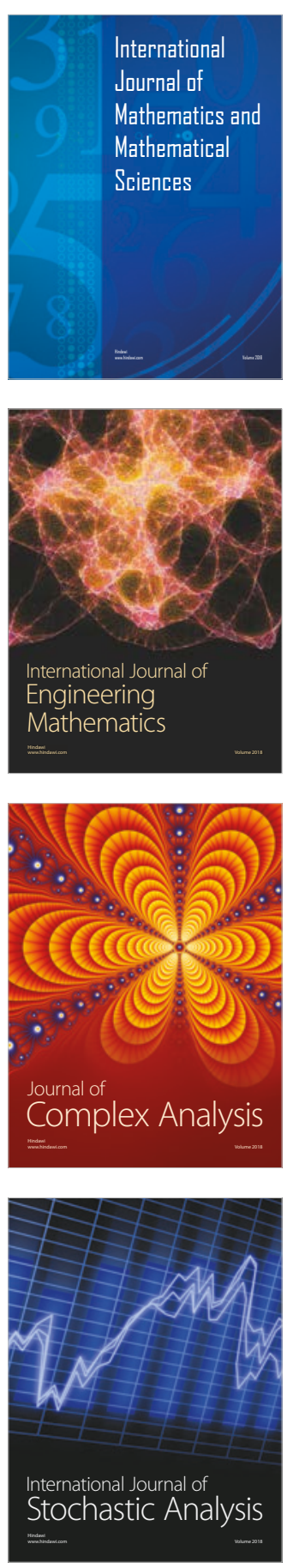
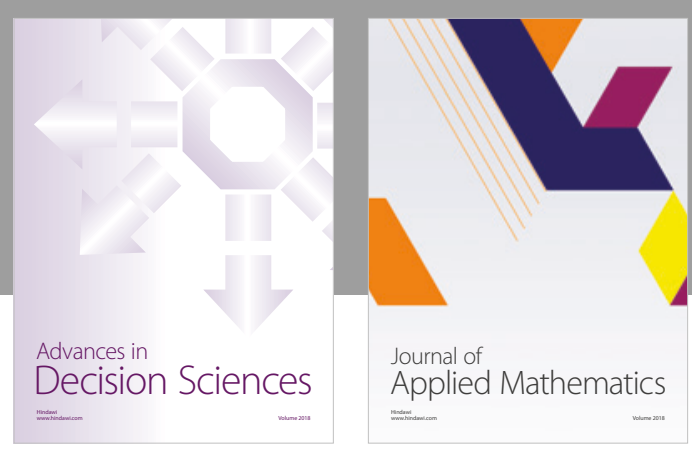

Journal of

Applied Mathematics
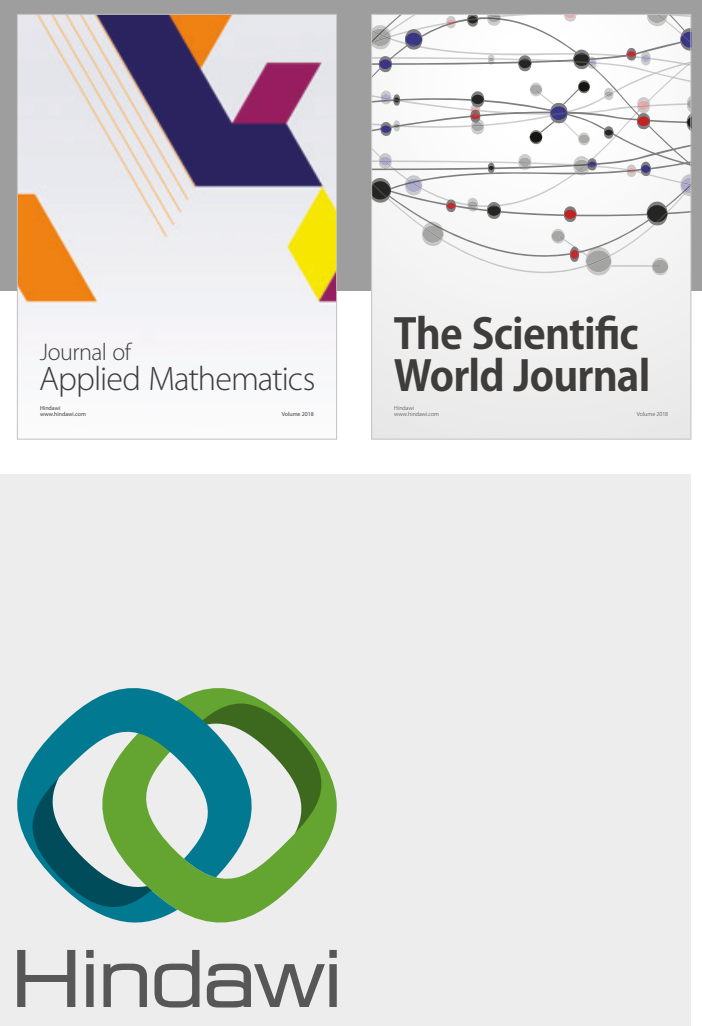

Submit your manuscripts at

www.hindawi.com

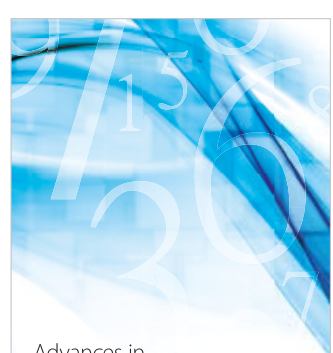

Advances in
Numerical Analysis
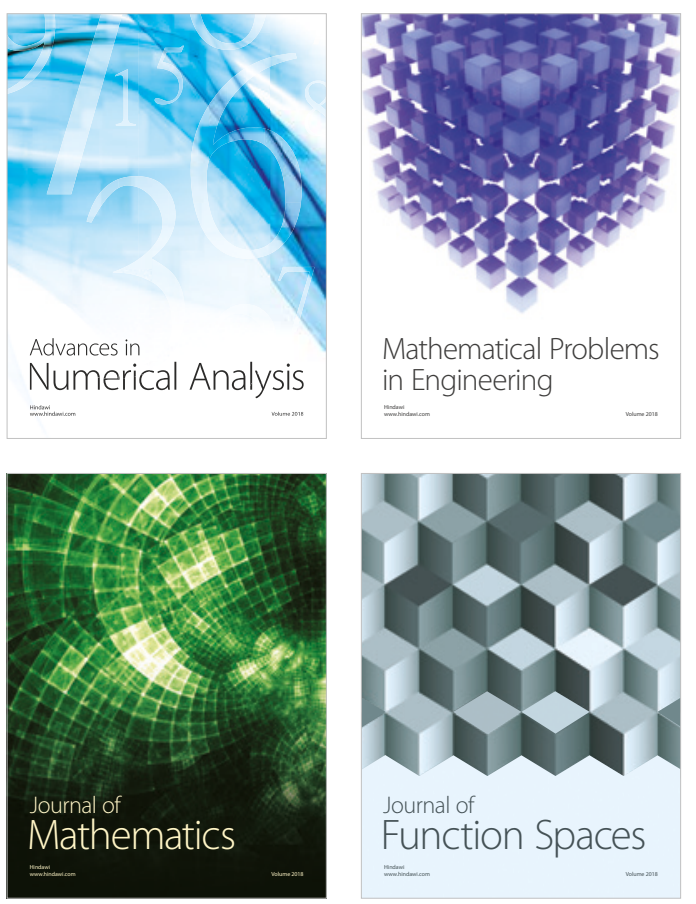

Mathematical Problems in Engineering

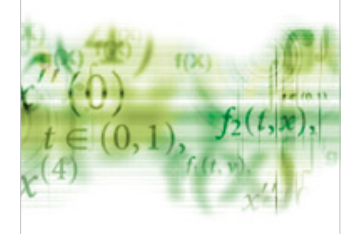

International Journal of

Differential Equations

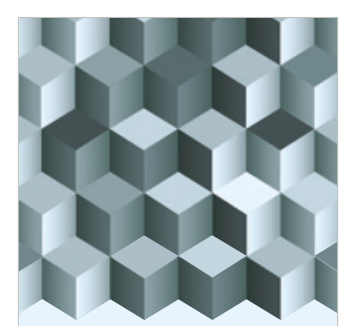

Journal of

Function Spaces

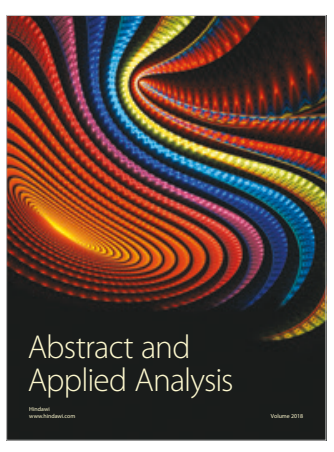

The Scientific

World Journal

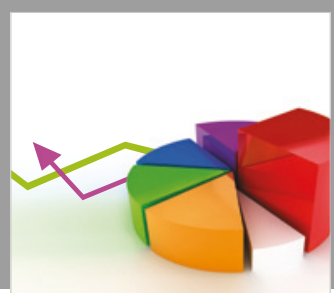

Journal of

Probability and Statistics
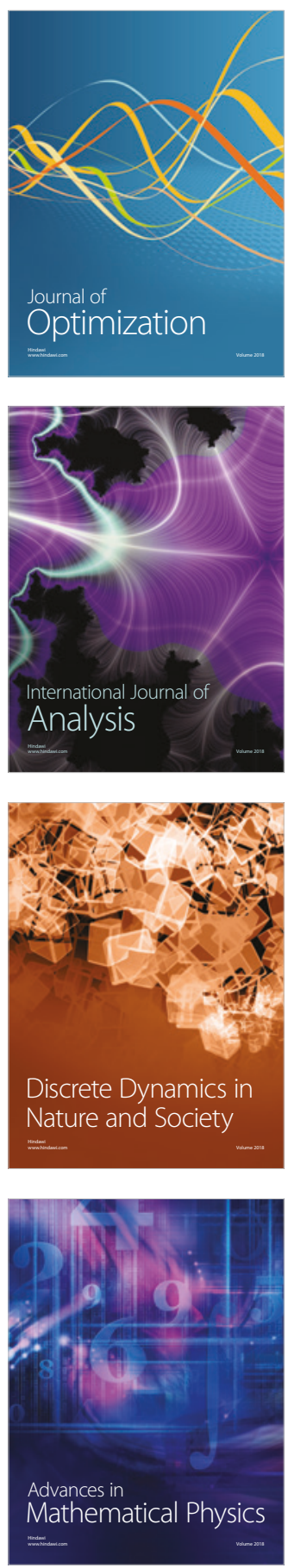